\title{
Article \\ Sustainable Preparation of Nanoporous Carbons via Dry Ball Milling: Electrochemical Studies Using Nanocarbon Composite Electrodes and a Deep Eutectic Solvent as Electrolyte
}

\author{
Ana T. S. C. Brandão (D), Renata Costa (D, A. Fernando Silva and Carlos M. Pereira *(D) \\ Departamento de Química e Bioquímica, Faculdade de Ciências da Universidade do Porto, CIQUP-Physical \\ Analytical Chemistry and Electrochemistry Group, Rua do Campo Alegre, s/n, 4169-007 Porto, Portugal; \\ up200706627@edu.fc.up.pt (A.T.S.C.B.); renata.costa@fc.up.pt (R.C.); afssilva@fc.up.pt (A.F.S.) \\ * Correspondence: cmpereir@fc.up.pt
}

\section{check for}

updates

Citation: Brandão, A.T.S.C.; Costa, R.; Silva, A.F.; Pereira, C.M. Sustainable Preparation of Nanoporous Carbons via Dry Ball Milling: Electrochemical Studies Using Nanocarbon Composite Electrodes and a Deep Eutectic Solvent as Electrolyte. Nanomaterials 2021, 11, 3258. https://doi.org/ $10.3390 /$ nano11123258

Academic Editor: Shenmin Zhu

Received: 3 November 2021

Accepted: 26 November 2021

Published: 30 November 2021

Publisher's Note: MDPI stays neutral with regard to jurisdictional claims in published maps and institutional affiliations.

Copyright: (c) 2021 by the authors. Licensee MDPI, Basel, Switzerland. This article is an open access article distributed under the terms and conditions of the Creative Commons Attribution (CC BY) license (https:/ / creativecommons.org/licenses/by/ $4.0 /)$.

\begin{abstract}
The urgent need to reduce the consumption of fossil fuels drives the demand for renewable energy and has been attracting the interest of the scientific community to develop materials with improved energy storage properties. We propose a sustainable route to produce nanoporous carbon materials with a high-surface area from commercial graphite using a dry ball-milling procedure through a systematic study of the effects of dry ball-milling conditions on the properties of the modified carbons. The microstructure and morphology of the dry ball-milled graphite/carbon composites are characterized by BET (Brunauer-Emmett-Teller) analysis, SEM (scanning electron microscopy), ATR-FTIR (attenuated total reflectance-Fourier transform infrared spectroscopy) and Raman spectroscopy. As both the electrode and electrolyte play a significant role in any electrochemical energy storage device, the gravimetric capacitance was measured for ball-milled material/glassy carbon (GC) composite electrodes in contact with a deep eutectic solvent (DES) containing choline chloride and ethylene glycol as hydrogen bond donor (HBD) in a 1:2 molar ratio. Electrochemical stability was tracked by measuring charge/discharge curves. Carbons with different specific surface areas were tested and the relationship between the calculated capacitance and the surface treatment method was established. A five-fold increase in gravimetric capacitance, $25.27 \mathrm{~F} \cdot \mathrm{g}^{-1}$ (G40) against $5.45 \mathrm{~F} \cdot \mathrm{g}^{-1}$, was found for commercial graphene in contact with DES. Optimal milling time to achieve a higher surface area was also established.
\end{abstract}

Keywords: graphite; graphene; ball-milling tools; deep eutectic solvent; specific surface area; capacitance; electrical double-layer capacitor

\section{Introduction}

Carbon nanomaterials such as graphene and graphite present unique physical, chemical and mechanical properties [1]. These carbon nanomaterials have attracted much interest for a large diversity of applications, from energy conversion (e.g., solar and fuel cells) [2-4] to energy storage (e.g., supercapacitors and batteries) [5-7] and remediation (e.g., removal of heavy metals from water and soils) [8,9].

When applied to energy storage, carbon and its derivatives are excellent candidates as electrode materials due to physicochemical properties such as a low atomic number, making it a lightweight material with long term stability, low residual current, and broad potential range. From an economic point of view, carbon is also an excellent candidate due to its abundance, with the existence of both natural and synthetic sources [1] offering many choices for porous electrode construction. Parameters such as material dimensionality, specific surface area, pore volume, pore size distribution, particle size, and texture can be easily tuned by controlling the synthetic route parameters [10].

Many different carbon materials have been prepared and tested for supercapacitor applications during the past 20 years. According to a literature survey, within this period, 
new methods have been introduced to prepare high-capacitance materials at the laboratory scale, according to several peer reviews [1,11-16]. The most commonly used type of carbon for capacitive technologies is activated carbon, being recognized as a disordered agglomeration of nanoscale units made of graphene layers randomly oriented and strongly cross-linked, presenting a high surface area [1]; however, the production of activated carbon requires a high amount of energy [17].

Graphene is an atomically thin two-dimensional $\mathrm{sp}^{2}$ bonded carbon sheet, exhibiting remarkable properties such as excellent thermal optical and electrical conductivity, mechanical strength, and remarkable electrochemical properties making it a promising active material for supercapacitors [18]. Graphene-based supercapacitors were reported by Vivekchand et al. [19] with a specific capacitance of $75 \mathrm{~F} \cdot \mathrm{g}^{-1}$ and an energy density of $31.9 \mathrm{~W} \cdot \mathrm{h} \cdot \mathrm{kg}^{-1}$, in ionic liquids, in a two-electrode system with an electrode mass of $5 \mathrm{mg}$, with a current density of $1 \mathrm{~A} \cdot \mathrm{g}^{-1}$ and charge-discharge under the interval 0-1 V. The BET surface area of the material was around $925 \mathrm{~m}^{2} \cdot \mathrm{g}^{-1}$, with an average pore size of $3 \mathrm{~nm}$. This technique is rather important for the characterization of carbon materials. Raman spectroscopy is also a commonly used method for carbon-based material characterization, offering information regarding chemical modification, crystallite size and crystal disorder [20], and its resolution has been evolving (super-resolution), with the imaging time being reduced considerably [21-23].

The routes to obtain graphene/graphene oxide/graphite oxide require high costs and are therefore not sustainable for industrial production [24]. Nowadays, the synthesis of these carbon materials can be made using environmentally-friendly methods, with the use of nontoxic chemicals [25].

Another possible route to synthesize graphitic materials is ball milling, known to be an effective and ecological way to prepare high surface area materials compared to other methods such as chemical exfoliation [26] and allowing the reduction of particle size and the refinement of grains to a size below $1 \mu \mathrm{m}$. The strong forces created between the high-speed rotating balls cause the mechanical cracking of the $\mathrm{C}-\mathrm{C}$ bonds and the subsequent exfoliation of the graphene sheets [26].

From a careful literature analysis, the available studies present very different experimental conditions and starting materials [27-32]. Therefore, a systematic study that can compare the effects of physical processing of carbon materials will allow a better understanding of the different contributions that influence the properties of carbon materials when subjected to mechanical treatment. Moreno-Fernández et al. [27] studied the effect of post-synthesis ball-milling of activated reduced graphene oxide on electrochemical performance, showing optimistic results with improved power density.

Although several types of electrolytes have been developed for supercapacitor applications and reported in the literature [30-40], high ionic concentration in the electrolyte is a prerequisite for capacitance improvement, and ionic liquids (ILs) present the required properties that make them suitable candidate [40-44]. Furthermore, ILs are less flammable when compared to common solvents, which contributes to improved safety issues and durability at high temperatures [45].

ILs are organic salts composed of organic cations and organic/inorganic anions, with high asymmetry and a solvent-free nature [46]. However, ILs present a high production and purification cost, which reduces their competitiveness when compared to traditional solvents. To overcome that situation, a solution can be found via the use of a new class of IL analogues known as deep eutectic solvents (DES), which present similar physical properties. DES are synthesized by complexing a quaternary ammonium salt with a variety of neutral, anionic and/or cationic species, namely metal chloride (type I), metal chloride hydrate (type II), a hydrogen bond donor (type III) or metal chloride hydrate complexed with a hydrogen bond donor (type IV) [47,48]. DES presents various advantages when compared to aqueous systems; better electrochemical stability, wider potential windows, and avoidance of gas evolution show that this new class of non-aqueous systems are the future of electrolytes for different applications [49-51]. 
In this work, commercial graphite was used as a starting material to prepare carbon nanomaterials through a dry ball milling processing. In this study, two different kinds of ball-milling equipment (Retsch Mixer Mill MM400 (Retsch GmbH, Haan, Germany) and IKA ULTRA-TURRAX ${ }^{\circledR}$ (IKA®-Werke GmbH \& Co., Staufen, Germany)) were used to modify commercial graphite powder. Commercial graphene and graphite were also used as reference materials to rate the structural and electrochemical performance of the modified graphite powders.

The dry ball-milling methods described in this work, may present a valuable route for obtaining nanoporous, high-specific surface area carbon materials through an innovative, easy, inexpensive, and environmentally - friendly route. Experimental data is interpreted based on surface interactions established between graphene/graphite-modified materials and type III DES electrolyte, composed of choline chloride and ethylene glycol as HBD, at a ratio of $1: 2$.

The obtained carbon nanomaterials will contribute to open the way to the development of easily obtainable electrodes for application in advanced electrochemical storage devices.

\section{Materials and Methods}

\subsection{Chemicals and Solvents}

Choline chloride (Sigma Aldrich, 99\% (Merck KGaA, Darmstadt, Germany)) was dried in the oven overnight at $60{ }^{\circ} \mathrm{C}$, before use; commercial graphene (platelets, $99.5 \%$, Iolitec Nanomaterials (IoLiTec-Ionic Liquids Technologies GmbH, Heilbronn, Germany)), commercial graphite (powder, Sigma Aldrich (Merck KGaA, Darmstadt, Germany)), ethylene glycol (EG) (Sigma Aldrich, 99+\% (Merck KGaA, Darmstadt, Germany)), Nafion TM 117 (Sigma Aldrich (Merck KGaA, Darmstadt, Germany)), and N, N-Dimethylformamide (DMF; Sigma Aldrich, 99.8\% (Merck KGaA, Darmstadt, Germany)) were used as received.

The eutectic mixture was formed by stirring the two selected components at $60{ }^{\circ} \mathrm{C}$ (proportions in Table 1) until a homogeneous, colorless liquid was formed. Prior to the electrochemical experiments, the solutions were de-aerated with nitrogen, and the cell was always kept under a nitrogen atmosphere.

Table 1. Composition and commercial designation of the DES used, with water content and viscosity measurements.

\begin{tabular}{|c|c|c|c|c|c|c|}
\hline DES & Composition & Molar Ratio & Choline Chloride & HBD & $\begin{array}{l}\text { Water Content } \\
\text { (wt.\%)** }\end{array}$ & Viscosity $(\mathrm{Cp})^{* * *}$ \\
\hline $\begin{array}{l}\text { ethaline } \\
200 * \\
(\mathrm{E} 200)\end{array}$ & $\begin{array}{c}\text { Choline } \\
\text { chloride }(\mathrm{ChCl}) \\
+ \text { ethylene } \\
\text { glycol (EG) }\end{array}$ & $1(\mathrm{ChCl}): 2 \mathrm{EG}$ & $-1 \mathrm{Cl}^{-}$ & & $8.8 \pm 0.5$ & $\begin{array}{l}30{ }^{\circ} \mathrm{C}: 64.3 \pm 1.3 \\
40^{\circ} \mathrm{C}: 48.7 \pm 1.8 \\
50{ }^{\circ} \mathrm{C}: 35.1 \pm 0.9 \\
60^{\circ} \mathrm{C}: 25.3 \pm 0.3\end{array}$ \\
\hline
\end{tabular}

* Trade name, ${ }^{* *}$ measured at room temperature, right after the DES preparation ${ }^{* * *}$ measured between $30-60{ }^{\circ} \mathrm{C}$, right after the DES preparation.

\subsection{Viscosity and Water Content of DES}

The dynamic viscosity of the DES was measured using the automated Anton Paar $\mathrm{DMA}^{\mathrm{TM}} 4500 \mathrm{M}$ microviscometer (Anton Paar GmbH, Graz, Austria), from 30 to $60{ }^{\circ} \mathrm{C}$.

Water content (wt.\%) was determined using a Karl Fischer titrator (831 KF Coulometer, Methrom (Herisau, Switzerland)) prior to the electrochemical studies. The sample solution was manually mixed to homogenize it before titrating, then $1 \mathrm{~mL}$ of sample was added to the dry methanol solvent (HYDRANAL ${ }^{\mathrm{TM}}$, max 0.01 wt.\% water, Riedel-de-Haën (Honeywell Specialty Chemicals Seelze GmbH Charlotte, EUA)) and titrated with HYDRANAL ${ }^{\mathrm{TM}}$ Composite 5 Reagent (4.5-5.5 mg. $\mathrm{mL}^{-1}$ water equivalent, Riedel-de-Haën (Honeywell Specialty Chemicals Seelze GmbH Charlotte, EUA)) for moisture determination. Measurements were performed in triplicate. 


\subsection{Electrochemical Measurements}

A three-electrode electrochemical cell consisting of a glassy carbon (GC) electrode (Methrom (Herisau, Switzerland), area $0.0721 \mathrm{~cm}^{2}$ ), a GC rod (Thermo Fisher (Kandel) $\mathrm{GmbH}$, Germany) as counter-electrode, and a silver wire (Thermo Fisher (Kandel) $\mathrm{GmbH}$, Germany) pseudo-reference electrode were used.

The preparation of the working electrode is described elsewhere [52,53]. Briefly, the working electrode was polished to a mirror-like finish before each experiment using $1 \mu \mathrm{m}$ diamond suspension (Buehler, IL, USA) followed by $0.5 \mu \mathrm{m}$ alumina powder (Buehler). The electrodes were rinsed with ultrapure water (purified through a Milli-Q Millipore system, Bioscience Research Reagents, CA, USA), followed by an electrochemical cleaning procedure using a sulphuric acid solution with a concentration of $0.5 \mathrm{~mol} . \mathrm{L}^{-1}$ until a stable cyclic voltammogram profile was obtained. The electrode was dried under a nitrogen flow prior to all measurements.

The immobilization of the carbon material was preceded by the preparation of a dispersion of $5 \mathrm{mg}$ of carbon in $950 \mu \mathrm{L}$ DMF and $10 \mu \mathrm{L}$ Nafion ${ }^{\circledR} 117$ mixture. Nafion was used as a binder to improve the adhesion of the material on the electrode surface. Binders such as Teflon, Nafion, and PVDF enhance the mechanical properties of films prepared from carbon particles, being typically used in supercapacitors, where they promote the performance stability over 5000 charge/discharge cycles [54]; however, they tend to introduce electric and ionic resistance to the electrode material. López-Chavéz [55] studied the effect of different binders, showing that is possible to use $1 \mathrm{wt} . \%$ Nafion solution as a binder with optimal electrode performance, reaching the maximum specific capacitance and minimum electric resistance contribution.

The dispersion went through ultrasonication for a given period $(2 \mathrm{~h})$ to obtain a homogeneous dispersion of the material. The amount of the carbon-coated on the GC electrode was obtained as an average of three measurements. The area density of the carbon material for the subsequent studies was calculated taking into consideration that the material and Nafion dispersion in DMF is homogeneous. The value of the area density was estimated to be $\sim 6.63 \times 10^{-3} \mathrm{~g} \cdot \mathrm{cm}^{-2}$.

To keep the dispersion subjected to the electrode's active surface while avoiding the surrounding Teflon part, several small amounts of the suspension were dropped on the glassy carbon electrode surface using a micropipette. In the present work, $10 \mu \mathrm{L}$ aliquots of the suspension were used for each of the five deposition stages. The electrode was left to dry at room temperature before use in the eutectic mixture.

The electrochemical measurements were performed using a computer-controlled AUTOLAB PSTAT 20 potentiostat/galvanostat from Eco Chemie, controlled by NOVA 2.1.5 software (Methrom (Herisau, Switzerland)). The experiments were performed at 30, 40,50 , and $60^{\circ} \mathrm{C}$. Voltammetric experiments were carried out at $50 \mathrm{mV} \cdot \mathrm{s}^{-1}$, starting at $0 \mathrm{~V}$ towards the positive side.

Electrochemical impedance spectroscopy spectra (EIS, Methrom (Herisau, Switzerland)) were collected in the range of $20 \mathrm{kHz}$ to $1 \mathrm{~Hz}$, with frequencies logarithmically distributed and a sinusoidal signal of $10 \mathrm{mV}$ (rms) superimposed over a dc potential. EIS measurements were made at $20 \mathrm{mV}$ intervals. The differential capacitance was obtained from the EIS measurements, and the impedance data were fitted to an equivalent circuit using Nova 2.1.5. software version.

All the procedures followed to extract the capacitance from the impedance data are described in a work published by Silva et al. [56]. The EIS spectra were fitted to a simple $\mathrm{R}-\mathrm{CPE}$ circuit, and the quality of the fitting was judged by the value of $\chi^{2}\left(<10^{-3}\right)$, as can be seen in Figure 1. In the absence of Faradaic processes at the electrode surface, the fitting of an R-CPE circuit to the impedance data measured at electrode/deep eutectic solvent shows a nearly vertical straight-line slope. 


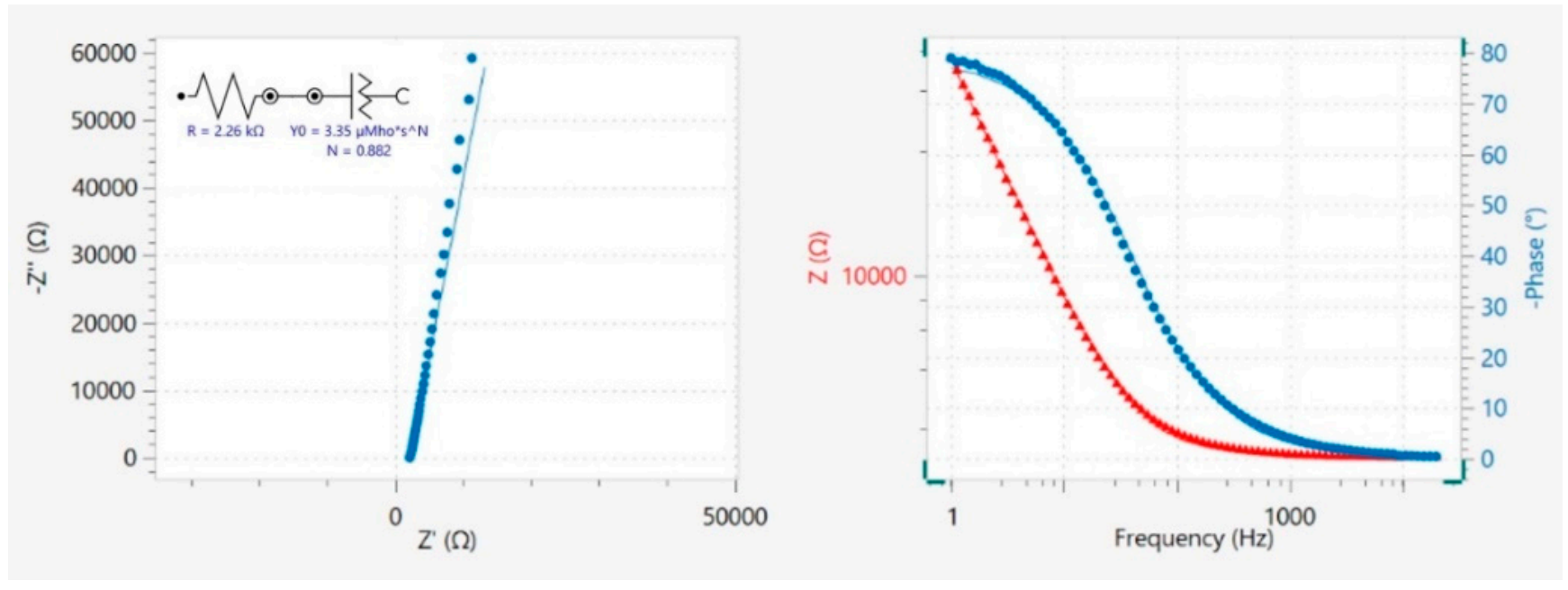

Figure 1. Nyquist diagram (-Z" vs. Z') and Bode plot ( $|Z|$ and $-\varphi$ vs. frequency) measured at the G_REF/E200, at 0.60 V, where experimental data (dots) and the line represent the fitting using an equivalent circuit R-CPE. Figure obtained from the NOVA 2.1.5 software.

The Nyquist complex plane impedance plot, Z" (imaginary) versus $Z^{\prime}$ (real), and Bode plot are presented in Figure 1 for G_REF/E200 at 0.60 V. The slight deviation observed on the Nyquist diagram to the real $Z^{\prime}$ axis points to an almost ideal capacitive behavior.

Galvanostatic charge/discharge curves were collected at current densities of 1,2, and $4 \mathrm{~A} \cdot \mathrm{g}^{-1}$. The specific capacitance in the three-electrode configuration was calculated from the galvanostatic discharge curves using Equation (1) as proposed by Stoller et al. [57].

$$
\mathrm{C}=\frac{\mathrm{I} \Delta \mathrm{t}}{\mathrm{m} \Delta \mathrm{V}}
$$

where I is the discharge current (A), $\Delta \mathrm{t}$ is the discharge time (s), $\Delta \mathrm{V}$ is the potential window $(\mathrm{V})$, and $\mathrm{m}$ is the weight of the carbon material in the electrode.

Although other methods for the calculation of the specific capacitance can be found in the literature (e.g. Vivekchand et al. [19]), we adopted Stoller et al.'s method [57], as the experimental conditions used in this work are closer to those described in the later publication. The method used by Vivekchand et al. [19] would give values systematically higher than those calculated using the method proposed by Stoller et al. [57].

According to Stoller et al. [57], the three-electrode cell can be used for the determination of the material's electrochemical specific characteristics, and provides the best indication of an electrode material's performance, while the two-electrode cell simulates the physical configuration, internal voltages, and charge transfer that occurs in a packaged supercapacitor. According to the same author [57], the cell should be cycled from $0 \mathrm{~V}$ to the maximum voltage ( $1 \mathrm{~V}$ in this case), because when a cell is first cycled or when it is cycled from a negative to a positive voltage there are increased current levels due to reversing the polarity of the cell.

\subsection{Carbon Material Modification}

The modification of the commercial graphite was performed by dry ball milling, using two different kinds of ball milling equipment, the IKA ULTRA-TURRAX ${ }^{\circledR}$ Tube Drive (IKA ${ }^{\circledR}$ - Werke GmbH \& Co., Staufen, Germany) (which allows grinding of a $15 \mathrm{~mL}$ volume sample, with $6 \mathrm{~mm}$ stainless steel balls $6000 \mathrm{rpm}$ maximum rotation), which is lighter and cheaper, and the Retsch Mixer Mill MM400 vibromachine (Retsch GmbH, Haan, Germeny) (which uses a single $3 \mathrm{~cm}$ stainless steel ball bouncing at $25 \mathrm{~Hz}$ ). Several treatments were made in the carbon materials; these experimental conditions are detailed in Table 2. 
Table 2. Treatment for carbon modifications and respective terminology.

\begin{tabular}{|c|c|c|c|c|}
\hline Carbon Material & Terminology & Code & Milling & Treatment \\
\hline Graphene* & $\begin{array}{l}\text { Commercial graphene }(11-15 \mathrm{~nm} \text {, } \\
99.5 \% \text {, Iolitec nanomaterials })\end{array}$ & G_REF & - & As received \\
\hline \multirow{3}{*}{ Graphite } & $\begin{array}{l}\text { Commercial graphite }(<20 \mu \mathrm{m}, \\
\text { synthetic, Sigma Aldrich })\end{array}$ & Graphite & - & As received \\
\hline & $\begin{array}{l}2000 \mathrm{rpm} \\
4000 \mathrm{rpm} \\
6000 \mathrm{rpm}\end{array}$ & $\begin{array}{l}\text { G@2000 } \\
\text { G@4000 } \\
\text { G@6000 }\end{array}$ & ULTRA-TURRAX ${ }^{\circledR}$ & $\begin{array}{l}\text { Ball milling for } 1 \mathrm{~h} \text { changing } \\
\text { the rotation speed }\end{array}$ \\
\hline & $\begin{array}{l}10 \mathrm{~min} . \mathrm{MM} 400 \\
20 \mathrm{~min} . \mathrm{MM} 400 \\
40 \mathrm{~min} . \mathrm{MM} 400 \\
60 \mathrm{~min} . \mathrm{MM} 400\end{array}$ & $\begin{array}{l}\text { G10 } \\
\text { G20 } \\
\text { G40 } \\
\text { G60 }\end{array}$ & Retsch MM400 & $\begin{array}{l}\text { Ball milling at } 25 \mathrm{~Hz} \\
\text { changing the milling time }\end{array}$ \\
\hline
\end{tabular}

* Reference graphene sample.

\subsection{Carbon Material Characterization}

Surface analysis was carried out using scanning electron microscopy, FEI Quanta 400 FEG/EDAX Genesis X4 M (FEI company, Hillsboro, OR, USA) at CEMUP. The image processing for the determination of the surface roughness ( $\mathrm{Ra}$ ) was performed using Gwyddion 2.53 software (Czech Metrology Institute, Okruzni, Czech Republic). Briefly, the SEM image was pre-processed. The preprocessing step included data leveling by mean plane subtraction, leveling of the data to make facets point upward, correcting lines by matching the height median, and correction of horizontal scars. The roughness parameters were evaluated using the roughness tool. The average roughness (Ra) was the result of the mean deviation of points from lines drawn across the sample image [58].

Atomic force microscopy (AFM) was performed using a Nano-Observer Atomic Force Microscope (PicoScan 2100, Les Ulis, France), operated in tapping mode and using SPM probes with a resonance frequency between 200 to $400 \mathrm{kHz}$. Image processing was performed with Gwyddion 2.53 software (Czech Metrology Institute, Okruzni, Czech Republic). The Ra parameter was obtained using the method presented above.

The surface area and pore parameters were determined using a nitrogen adsorption analyzer (TriStar Plus, Micromeritics, Norcross, GA, USA).

Attenuated total reflectance infrared measurements were performed using a Bruker FT-IR System Tensor 27 spectrophotometer (Systems Chemistry, Institute for Molecules and Materials, Heyendaalseweg, Netherlands) in the range of 4000 to $600 \mathrm{~cm}^{-1}$.

Raman spectra of the samples were recorded with a Raman spectrometer, Ramos PA532 Ostec (Moscow, Russia), using a $532 \mathrm{~nm}$ excitation wavelength. To perform the experiments, $200 \mathrm{mg}$ of carbon material was previously dried overnight in the oven at $50{ }^{\circ} \mathrm{C}$ followed by at least $2 \mathrm{~h}$ under nitrogen flow.

\section{Results and Discussion}

\subsection{Viscosity and Water Content of Ethaline 200}

Water content is a parameter that can affect the physical properties of DES [47-49], namely the viscosity. Viscosity and water content are recognized as important characteristics of ionic solvents which influence their electrochemical performance.

Results for viscosity and water content are presented in Table 1 for temperatures between $30^{\circ} \mathrm{C}$ and $60^{\circ} \mathrm{C}$. These data are in agreement with those of Salomé et al. [52], where a viscosity value of $16 \mathrm{cP}$ was obtained at $75^{\circ} \mathrm{C}$.

No efforts were made to reduce the water content since we aimed in this work to use a straightforward procedure that would not require the use of a glove box to perform the electrochemical characterization of the carbon materials. 


\subsection{Characterization of the Carbon Materials}

\subsubsection{Surface Area by Brunauer-Emmet-Teller Method}

For a deeper understanding of the effect of milling on the morphology and specific area of the carbon materials, the specific surface area and micropore volume of commercial graphene, commercial graphite, and modified carbon materials were calculated from $\mathrm{N}_{2}$ adsorption-desorption isotherms using the Brunauer-Emmet-Teller (BET) method as presented in Table 3.

Table 3. Surface area, pore volume, and specific capacitance determined for commercial graphene (G_REF), commercial graphite, and commercial graphite subjected to milling using a Retsch Mixer Mill MM400 (samples G10, G20, G40 and G60) and IKA ULTRA-TURRAX ${ }^{\circledR}$ Tube Drive (samples G@2000, G@4000 and G@6000). Specific capacitance was evaluated at the interface between the composite graphite/E200 with current density $1 \mathrm{~A} \cdot \mathrm{g}^{-1}$, at $30^{\circ} \mathrm{C}$.

\begin{tabular}{|c|c|c|c|}
\hline Samples & $\mathrm{S}_{\mathrm{BET}}\left(\mathrm{m}^{2} \cdot \mathrm{g}^{-1}\right)$ & Pore Volume $\left(\mathrm{cm}^{3} \cdot \mathrm{g}^{-1}\right)$ & Specific Capacitance $\left(\mathrm{F} \cdot \mathrm{g}^{-1}\right)$ \\
\hline G_REF & 45.14 & 0.00461 & $5.45 \pm 0.96$ \\
\hline Graphite & 10.74 & 0.00028 & $4.27 \pm 0.85$ \\
\hline G10 & 18.15 & 0.00050 & $2.36 \pm 0.21$ \\
\hline G20 & 235.80 & 0.02227 & $24.83 \pm 2.33$ \\
\hline G40 & 308.58 & 0.03163 & $25.10 \pm 2.22$ \\
\hline G60 & 41.84 & 0.00419 & $4.19 \pm 1.01$ \\
\hline G@2000 & 9.81 & 0.00103 & $1.95 \pm 0.35$ \\
\hline G@4000 & 10.80 & 0.00081 & $2.57 \pm 0.44$ \\
\hline G@6000 & 11.33 & 0.00088 & $2.59 \pm 0.31$ \\
\hline
\end{tabular}

Graphene presents a BET specific surface area of $45.14 \mathrm{~m}^{2} \cdot \mathrm{g}^{-1}$ and a pore volume of $0.0046 \mathrm{~cm}^{3} \cdot \mathrm{g}^{-1}$ as measured by nitrogen adsorption at $77 \mathrm{~K}$. On the other hand, graphite presents a BET specific surface area of $10.74 \mathrm{~m}^{2} \cdot \mathrm{g}^{-1}$ and a much smaller pore volume of $0.00028 \mathrm{~cm}^{3} \cdot \mathrm{g}^{-1}$.

Commercial graphene presents different values of specific surface area depending on the manufacturer; however, theoretical calculations predict a large surface area of single-layer graphene close to $2600 \mathrm{~m}^{2} \cdot \mathrm{g}^{-1}$ [59]. Wasalathilake et al. [60] prepared graphene-based material displaying a specific area of $384.4 \mathrm{~m}^{2} \cdot \mathrm{g}^{-1}$ with a pore volume of $0.73 \mathrm{~cm}^{3} \cdot \mathrm{g}^{-1}$. The commercial graphene used in this study presents significantly lower values of specific surface area and pore volume, showing that the present commercial graphene sheets are less exposed.

The BET specific surface area determined for G_REF is approximately four times higher than that obtained for graphite powder, which is expected and in agreement with other experimental results, likely because graphite can suffer from overlapping and agglomeration of layers [61] as a consequence of the van der Waals interactions that can occur between the graphene sheets [53].

The effect on the surface area and pore volume of milling the graphite reference material for 10, 20, 40, and 60 min with the Retsch Mixer Mill MM400 equipment is also presented in Table 3. Increasing the ball milling time leads to an increase in the surface area and pore volume. For 10 min of milling, the increase is small (an almost two-fold increase in in the surface area and pore volume), while for $20 \mathrm{~min}$ milling time there is a marked increase in the surface area (20 times higher) and pore volume (80 times higher), reaching the maximum at 40 min milling time with a surface area of $308.6 \mathrm{~m}^{2} \cdot \mathrm{g}^{-1}$ and a pore volume of $0.03163 \mathrm{~cm}^{3} \cdot \mathrm{g}^{-1}$. Further increases in milling time result in a decrease of both surface area and pore-volume; nevertheless, the surface area $(4 \times)$ and pore volume $(15 \times)$ values are higher when compared to commercial graphite. A similar trend has been previously reported for milled graphite in work performed by Disma et al. [62] and Welham et al. [63]. Disma et al. [62] referred that the specific surface area of the ball-milling samples increased with the ball-milling time until a critical time was achieved, followed by a decrease. Following the same line of thought, Welham et al. [63] suggested that 
after the maximum surface area is reached, particles were rewelded, leading to a decrease in surface area (breakage/rewelding process). Chen. et al. [64] concluded that milling contamination did not affect the formation of this nanoporous structure. Similar results were reached by Zhang et al. [65] for ball-milled activated carbon, in which the specific surface area and pore volume diminished from $2137 \mathrm{~m}^{2} \cdot \mathrm{g}^{-1}$ to $1683 \mathrm{~m}^{2} \cdot \mathrm{g}^{-1}$, and 0.95 $\mathrm{cm}^{3} \cdot \mathrm{g}^{-1}$ to $0.78 \mathrm{~cm}^{3} \cdot \mathrm{g}^{-1}$, respectively, after $8 \mathrm{~h}$ of ball-milling. Mhadhbi et al. [66] used the discrete element method to simulate the correlation between several milling parameters (e.g., geometry, number, and size of balls and speed). The results showed that lower mass can improve milling performance, with the stainless-steel balls presenting a positive effect on milling efficiency as well as an increase in the milling velocity.

For further comparison, a parallel study was performed for graphite powder ball-milled with cheaper equipment, the IKA ULTRA-TURRAX ${ }^{\circledR}$ Tube Drive ball miller.

The surface areas of the samples were determined using the BET procedure, with the obtained results presented in Table 3.

The products dry milled with stainless steel balls present an average surface area of $9.81,10.80$, and $11.33 \mathrm{~m}^{2} \cdot \mathrm{g}^{-1}$ in samples obtained at different mill speed rotations of 2000, 4000, and $6000 \mathrm{rpm}$, respectively. G@2000 presented the highest pore volume, while G@6000 presented the highest surface area. Adsorption-desorption experiments established the existence of micropores with a pore volume approximately $29 \times$ smaller than those obtained by the Retsch Mixer MM400 milled samples. Although the Tube Drive ball miller can induce some transformation of the carbon material, this process lacks the energy to promote the structural changes required to form graphene sheets. In fact, for short rotations (2000 rpm) of Tube Drive ball milling, there is a reduction of surface area, probably due to the increase in particle agglomeration.

\subsubsection{Scanning Electron Microscopy Characterization}

SEM imaging can contribute to the qualitative characterization of a material's morphological structure (e.g., by allowing the comparison of the surface topography, composition, and the distribution of microscopic hollows in composites).

The morphology of the composite electrodes with G_REF and graphite samples were analyzed by SEM, and the images are represented in SI in Figure S1a,b, respectively.

The result of SEM G_REF at low magnification (5000× magnification) shows the existence of fewer stacks, with a smoother build-up morphology and larger inter-zone separation compared with the SEM image obtained for the graphite sample. The SEM images also show that the graphite has a more layered structure. The G_REF morphology presents a slight ripple and uniform surface compared with graphite, and shows randomly arranged aggregates, forming more irregular and closely spaced graphite microzones in the composite film (magnification 10,000 $\times$ ).

The SEM analysis agrees with the data collected from the BET analysis. The SEM images show distinct morphological differences between both composite electrodes (e.g., clear, and well-defined graphene sheets compared to smaller agglomerates obtained in the graphite sample), which may lead to a lower superficial area. The morphology of G10, G20, G40, and G60 was investigated via SEM (with representative micrographs presented in Figure 2), with magnifications of $5000 \times$ and 10,000 $\times$.

SEM micrographs from the surface analysis of the composite morphology with increasing time of the ball milling treatment show a noticeable change in the morphology of the carbon materials. 

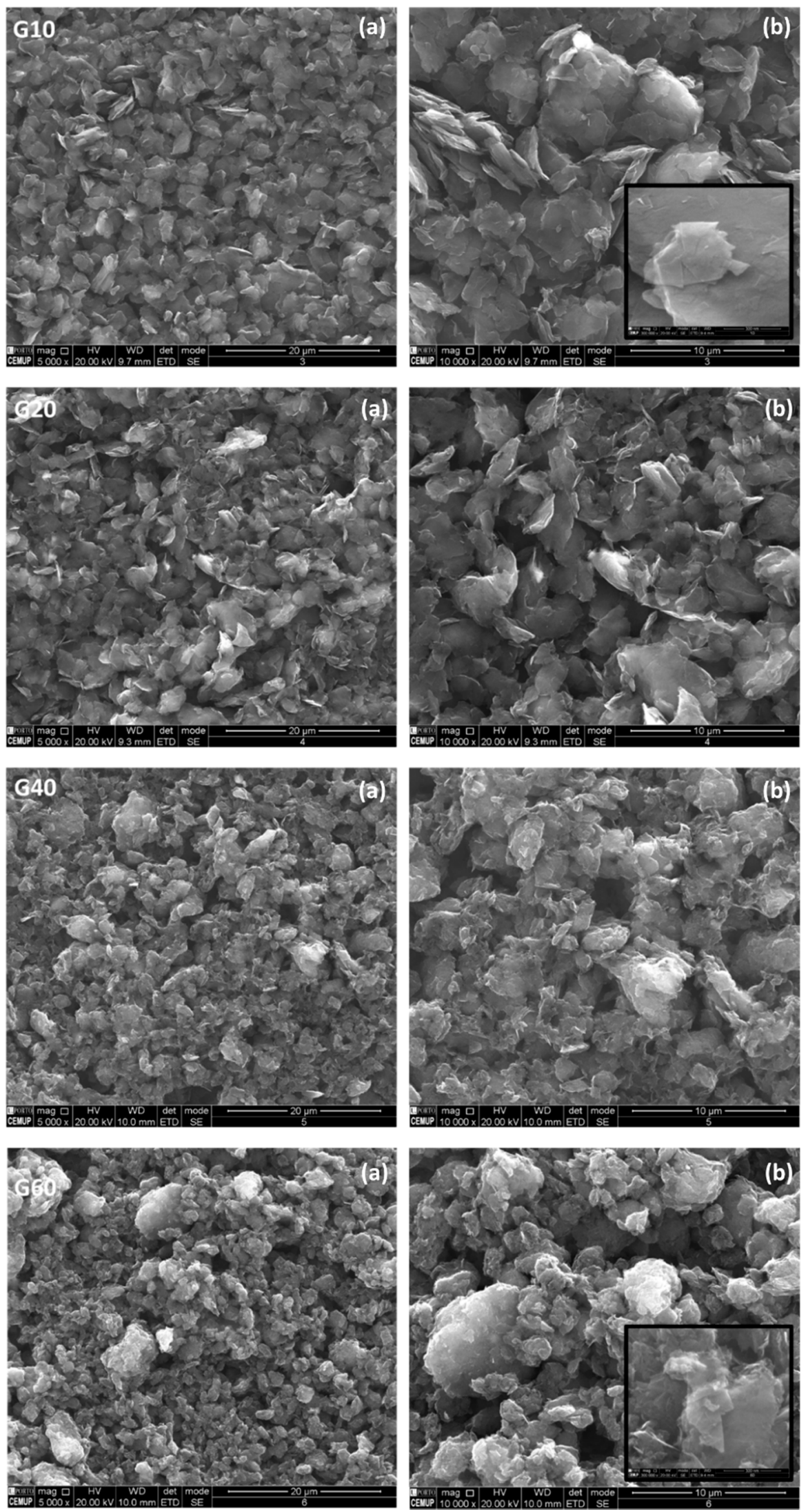

Figure 2. Electron microscopy images showing the structure of G10, G20, G40, and G60 samples with $5000 \times(\mathbf{a})$ and $10,000 \times(\mathbf{b})$ magnification. Inset images in Samples G10 and G60 present a $300,000 \times$ magnification. 
SEM images regarding the ball-milled graphitic samples using the MM400 equipment show that the range of particle size in the milled samples is wider compared with the graphene reference sample and the unmilled graphite powder. The SEM micrographs show particles with a flat shape (flake type) and with evidence for the presence of facets with treatments shorter than $40 \mathrm{~min}$. The SEM image obtained for the G60 sample indicates that the particles tend to agglomerate, forming larger aggregates. This may be the reason for the lower specific area and pore volume obtained for this sample. By increasing the magnification of the image (which allows a closer examination of the large aggregates that present some faceting), however, the majority have a rounded shape, representing the possibility of the loss of edges due to abrasion during the milling process. Consequently, $40 \mathrm{~min}$ of milling seems to lead to a size reduction by fracturing the larger particles into smooth and smaller ones; however, when the optimal milling time is exceeded, it seems that the smaller particles themselves become agglomerated (approx. 5-10 $\mu \mathrm{m}$ ). The fracturing procedure of large clusters is no longer in equilibrium with the agglomeration trend of small particles; subsequently, the surface area begins to drop [64].

The graphite dry ball-milling procedure seems to promote the generation of a new surface that may be accompanied by the increase in surface area concomitant with a reduction in particle size, signifying that no large clusters can be formed [67]. The arrangement of these large clusters will influence the complex surface area trend, as supported by BET analysis during the additional milling period.

The SEM and BET data strongly suggest that many micropores were created in the first stage of the milled graphite sample by the ball milling tools, resulting in particle fracture induced by ball impacts. The subsequent reduction reported in BET surface area analysis is associated with agglomeration effects (larger clusters; [64]), which are evident in the G60 SEM micrograph (Figure 2).

The SEM micrographs of IKA ULTRA-TURRAX ${ }^{\circledR}$ material (Figure S2) ball-milled samples reveal an insignificant modification in the sample morphology after ball milling compared with the starting material's flake-like structure. The impact forces from ball collisions seem not to cause relevant mechanical stress in graphite structure compared with the Retsch Mixer Mill. Despite the SEM images obtained for the G@2000 sample, it seems to be more uniform, probably caused by the sliding of the graphite layers. The IKA ULTRA-TURRA ${ }^{\circledR}$ ball milling procedure did not effectively thin or break the graphite particle down further, presenting a specific area lower than the graphene reference material, and similar values to the starting graphite material.

Surface roughness is also a parameter that needs to be considered more accurately to enhance electrical properties. Several authors have shown that capacitance increases with surface roughness [68-70]. The surface roughness determination was performed through the analysis of the SEM images. The surface roughness $\left(R_{a}\right)$ for the different carbon materials is presented in Figure 3, with the associated standard deviation for each sample.

These results show that surface roughness is strictly associated with the variation of $\mathrm{S}_{\mathrm{BET}}$, showing that the increase of $\mathrm{S}_{\mathrm{BET}}$ leads to an increase in the surface roughness of the carbon material, with the G40 sample presenting a maximum surface roughness of $75 \mathrm{~nm}$, against $49 \mathrm{~nm}$ for the commercial graphite.

AFM analysis of the topography of the ball-milled samples (G10 to G60) was also performed (Figure S3, in SI) to complement the SEM studies, and the $\mathrm{R}_{\mathrm{a}}$ parameter (Figure S4, in SI) was also determined, following the same method presented above. The topography at both magnifications ( $50 \mu \mathrm{m} \times 50 \mu \mathrm{m}$ and $10 \mu \mathrm{m} \times 10 \mu \mathrm{m})$ shows that there is a uniform dispersion of the carbon materials on the GC electrode's surface. There is a visible increase in grain size in samples G20 and G40, where the $R_{a}$ obtained through AFM analysis presents the same tendency as presented in Figure 3, with G40 presenting a maximum surface roughness of $189 \mathrm{~nm}$. The discrepancy in the obtained values is due to the different characterization techniques. 


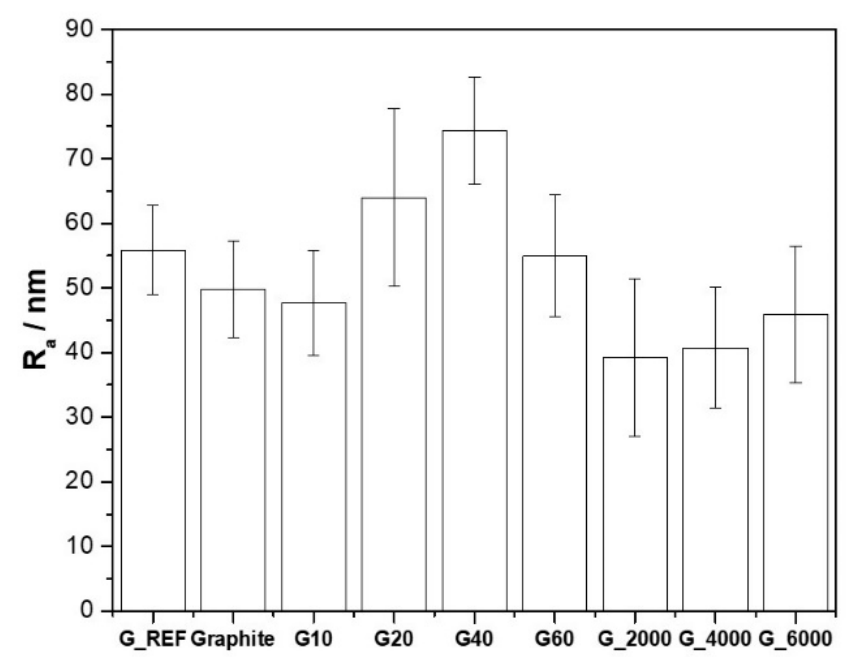

Figure 3. Surface roughness $\left(R_{a}\right)$ for the different carbon materials.

\subsubsection{ATR-IR and Raman Spectroscopy Characterization}

ATR-IR and Raman spectroscopy methods were also used for the characterization of the samples to study the evolution of the vibrational spectrum of the G_REF and modified samples due to the ball-milling process.

Figure 4 shows the ATR-IR spectra of G_REF, graphite, and ball-milled graphite samples. All samples present very similar peaks with different intensities.

G_REF and graphite ATR-FTIR analysis is shown in Figure 4a, presenting three prominent peaks (1922 $\mathrm{cm}^{-1}$ and $2112 \mathrm{~cm}^{-1}$, coincident for both materials, and at $2330 \mathrm{~cm}^{-1}$ and $2331 \mathrm{~cm}^{-1}$ for graphite and G_REF, respectively). These peaks are related to the $\mathrm{C}=\mathrm{O}$ bond stretching vibration from the gaseous $\mathrm{CO}_{2}$ presented in the atmosphere and absorbed on the walls of the porous carbon structure [71]. The peak intensity related to the $\mathrm{C}=\mathrm{O}$ bond is determined by the concentration of the impurities and the thickness of the carbon structure [72], with both samples presenting the same peak intensity.

Three peaks appear between $3000-4000 \mathrm{~cm}^{-1}\left(3631 \mathrm{~cm}^{-1}, 3745 \mathrm{~cm}^{-1}\right.$, and $\left.3850 \mathrm{~cm}^{-1}\right)$ for both G_REF and commercial graphite, suggesting the possibility of adsorbed water molecules being due to the $-\mathrm{OH}$ stretching fundamental vibration $\mathbf{v}_{3}$ and $\mathbf{v}_{1}$ in the water monomer [73-75], with a higher intensity in commercial graphite. In G_REF, a low-intensity peak appears at $3000 \mathrm{~cm}^{-1}$, related to the $\mathrm{C}-\mathrm{H} \mathrm{sp} \mathrm{s}^{2}$ bond from the graphitic aromatic ring [71]. Huang et al. [76] and Ciplak et al. [77] performed ATR-IR analysis of graphene, presenting similar peaks.

Figure $4 \mathrm{~b}$ shows the ATR-IR analysis for the ball-milled graphite samples through the MM400 equipment. All peaks previously stated for G_REF and graphite are present in all MM400 ball-milled samples, with higher peak intensity when compared to the commercial graphite and G_REF samples. The G40 sample presents the peaks with higher intensity, which can be associated with the sample with higher surface area, in which the peak intensity is well correlated with the surface area obtained from the BET method, indicating a higher $\mathrm{CO}_{2}$ and water absorption due to the higher exposed area of the carbon material. G40 and G10 transformed the three peaks between 3000 and $4000 \mathrm{~cm}^{-1}$ into a single peak very close to $3746 \mathrm{~cm}^{-1}$. The same behavior is presented in Figure $4 \mathrm{c}$ for the Ultra-Turrax ball-milled samples, with G@2000 presenting a single peak at $3000-4000 \mathrm{~cm}^{-1}$ compared with the three peaks presented by the other samples. This might be related to the broadening of the peaks associated with higher $-\mathrm{OH}$ bonding interaction, creating higher disorder due to the higher inhomogeneity of the samples [78]. Figure $4 b, c$ present a peak around $1600 \mathrm{~cm}^{-1}$ for the ball-milled samples for the $\mathrm{O}-\mathrm{H}$ groups from water molecules [71], presenting the same tendency regarding the three peaks appearing between $3000-4000 \mathrm{~cm}^{-1}$. 


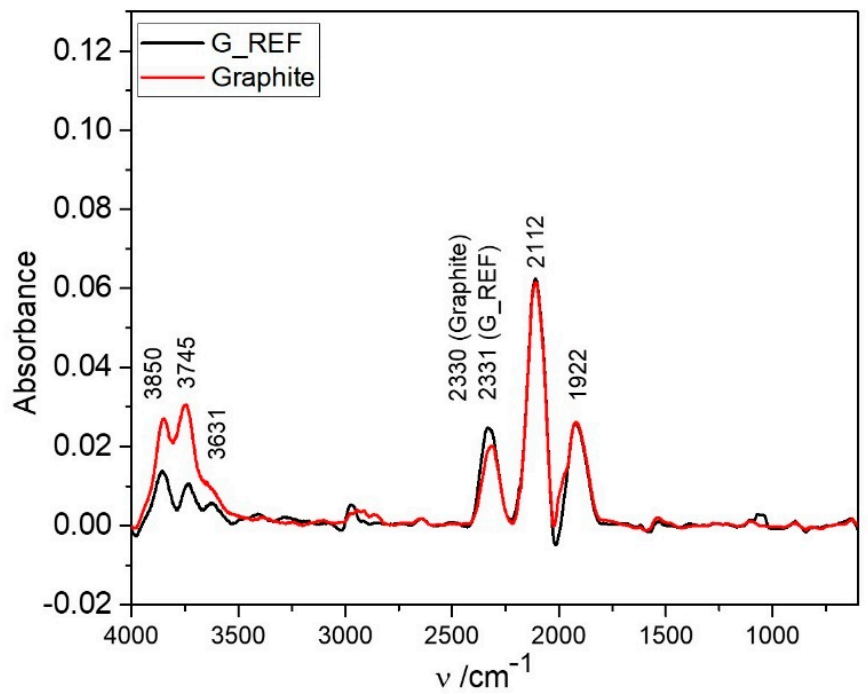

(a)

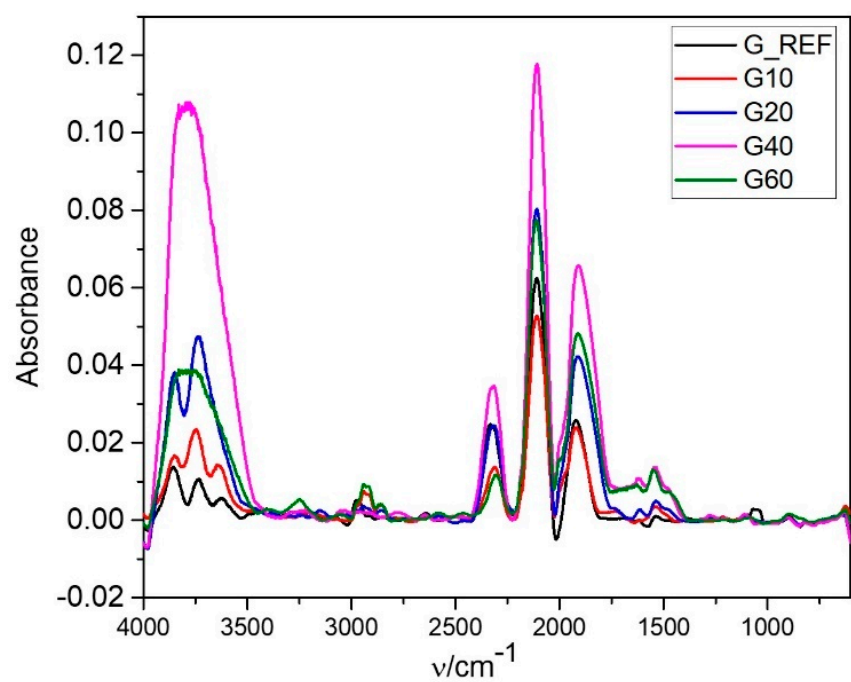

(b)

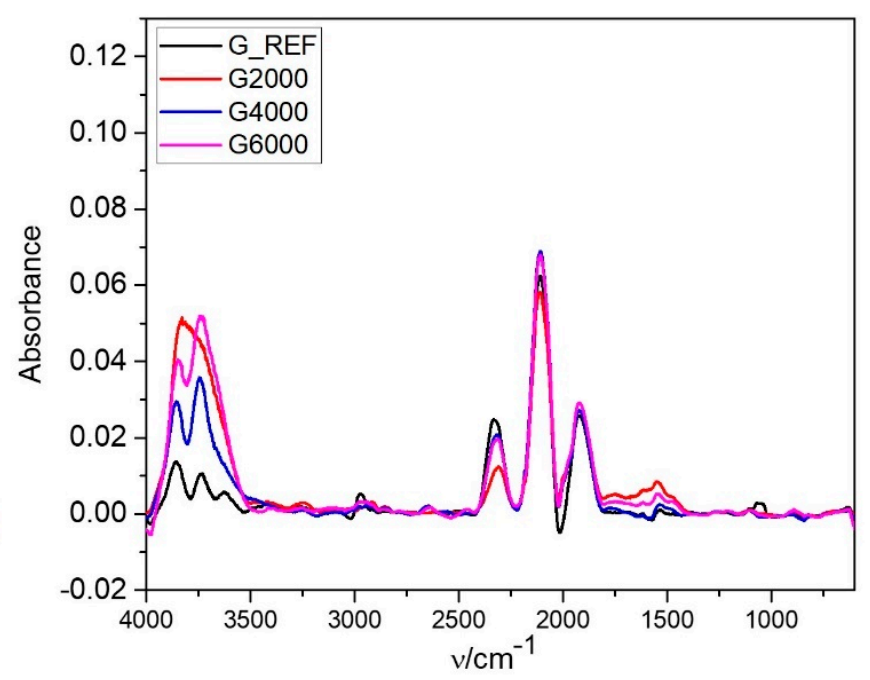

(c)

Figure 4. ATR-IR spectrum of commercial graphene (G_REF), commercial graphite (a), and modified graphene samples through the two different ball milling processes $(\mathbf{b}, \mathbf{c})$.

To confirm the ATR-IR analysis, Raman spectroscopy was used for the characterization of the studied carbon materials to focus on the characteristic peaks associated with graphitic-based materials. Raman spectra related to the first order Raman region of G_REF and commercial graphite is presented in Figure 5a, followed by the modified graphite samples through MM400 ball-milling (Figure $5 \mathrm{~b}$ ) and Ultra-Turrax ball-milling (Figure 5c).

The Raman spectra of all the studied samples are presented in SI (Figures S5-S13), alongside the deconvolution study for the $\mathrm{D}$ and $\mathrm{G}$ bands. In this study, special attention has been given to the Raman region between 1000 and $2000 \mathrm{~cm}^{-1}$. The Raman region higher than $2000 \mathrm{~cm}^{-1}$ includes the 2D Raman mode, being the strongest Raman mode in single-layer graphene [79], and two D band phonons with opposite, non-zero momentum. In the studied samples, the intensity of the $2 \mathrm{D}$ band $\left(\sim 2900 \mathrm{~cm}^{-1}\right.$ [79]) is insignificant, which indicates that we are dealing with multilayer graphene $\left(\mathrm{I}_{2 \mathrm{D}} / \mathrm{I}_{\mathrm{G}}<0.5[80]\right)$. Therefore, the deconvolution of the Raman bands was performed only for the D and $G$ bands. 


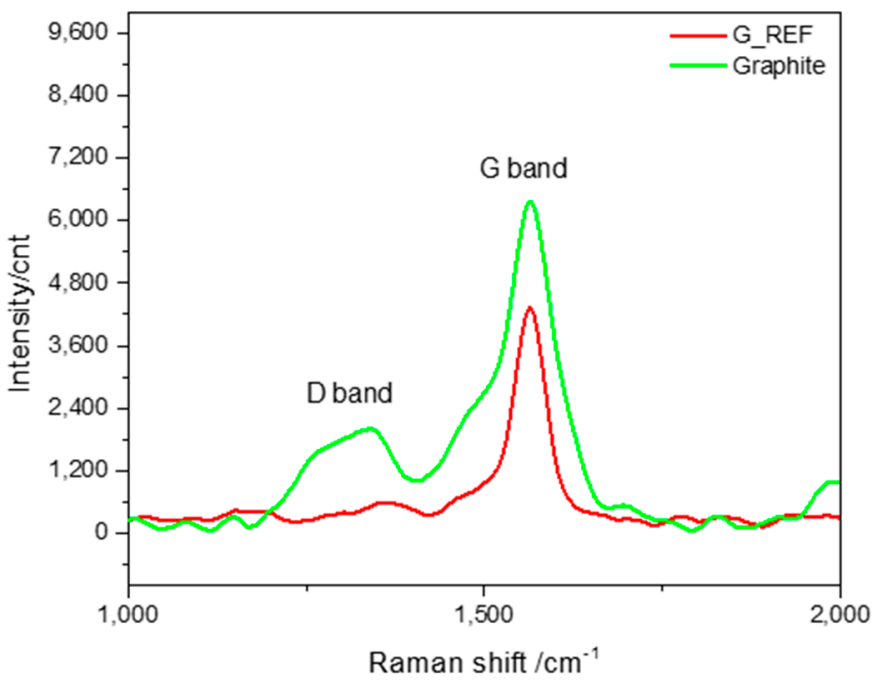

(a)

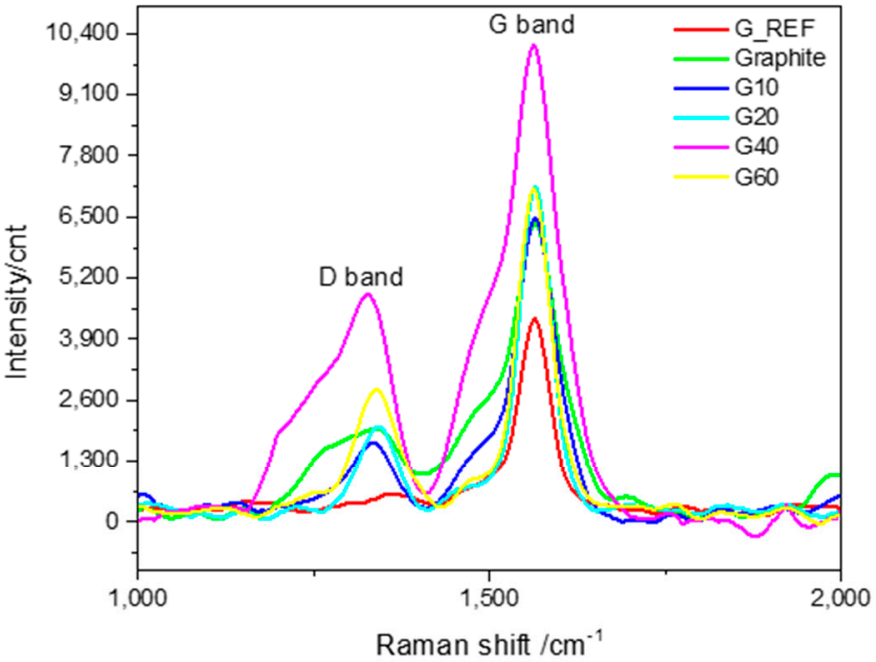

(b)

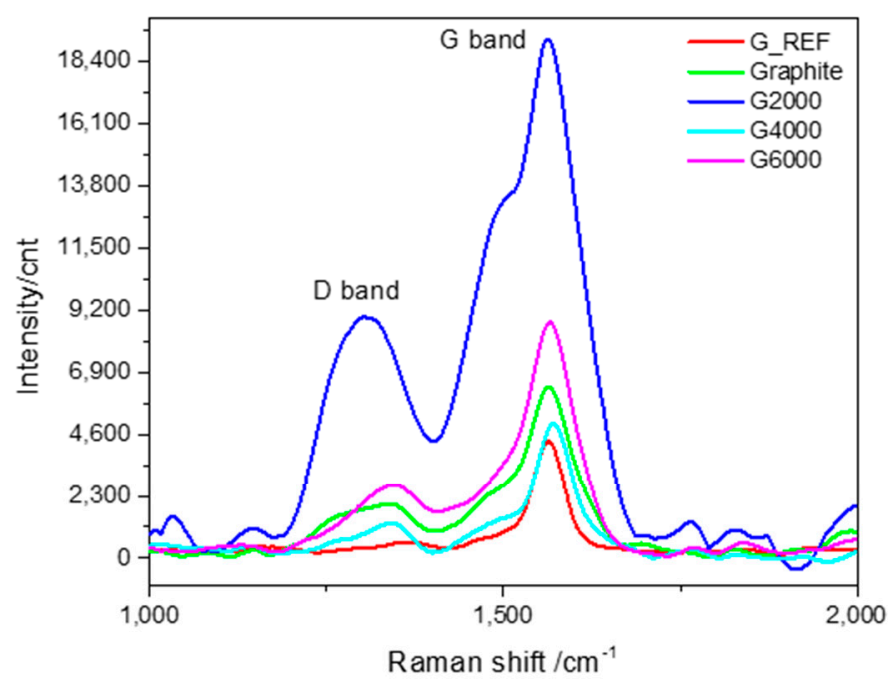

(c)

Figure 5. Raman spectra (1000-2000 $\mathrm{cm}^{-1}$ ) of (a) G_REF and commercial graphite, (b) MM400 ball-milled graphitic samples, and (c) Ultra-Turrax ball-milled graphitic samples.

As expected for carbon-based materials, all studied samples reveal the $\mathrm{D}\left(\sim 1350 \mathrm{~cm}^{-1}\right)$ and $\mathrm{G}\left(\sim 1600 \mathrm{~cm}^{-1}\right)$ bands [81-83].

For all the Raman spectra of the studied graphitic materials, the first order region was deconvoluted into five peaks (D4, D1, D3, G, and D2) using the Gauss function (Figures S5-S13) [84-88].

The $\mathrm{G}$ band is a sharp band appearing around $1600 \mathrm{~cm}-1$ in the spectrum of graphene, and it is associated with single-crystal graphite $[84,89,90]$. The $G$ band originates from the stretching of the $\mathrm{C}-\mathrm{C}$ bond in the hexagonal plane and is common to all $\mathrm{sp} 2$ carbon systems [91]. Table S1, in SI, summarizes the main results regarding the Raman spectra of the different studied carbon materials.

The $\mathrm{D}$ band is known as the disorder or defect band, representing a ring breathing mode from $\mathrm{sp}^{2}$ carbon rings [82]. The intensity of the $\mathrm{D}$ band is directly proportional to the level of defects in the sample [89]. For all the G_REF, commercial graphite, and ball-milled graphitic samples, the $\mathrm{D}$ band is around $1350 \mathrm{~cm}^{-1}$. 
Figure 5 reveals the increase in the intensity of the $D$ and $G$ bands with the increase in ball-milling time for the MM400 samples (G10, G20, G40, and G60), except for the G60 sample, which presents a decrease in intensity. The same tendency is not observed for the Ultra-Turrax ball-milling samples, showing inconsistent behavior.

The degree of disorder and the average size of the in-plane $\mathrm{sp}^{2}$ domains are determined from the intensity ratio of the $\mathrm{D}$ and $\mathrm{G}$ bands $\left(\mathrm{I}_{\mathrm{D}} / \mathrm{I}_{\mathrm{G}}\right)$ [90]. The $\mathrm{I}_{\mathrm{D}} / \mathrm{I}_{\mathrm{G}}$ ratio for the different samples is presented in Table $\mathrm{S} 1$, showing that the ratio $\mathrm{I}_{\mathrm{D}} / \mathrm{I}_{\mathrm{G}}$ ratio of G_REF is almost half compared to graphite ( 0.15 and 0.26 , respectively), indicating that the G_REF sample presents far fewer defects in its carbon structure. Taking into consideration the MM400 ball-milling samples, the $\mathrm{I}_{\mathrm{D}} / \mathrm{I}_{\mathrm{G}}$ ratio increases with the increase in ball-milling time, decreasing only for the G60 sample, thus showing that the increased level of defects is strictly associated with the increase in specific surface area, suggesting the formation of new domains of conjugated carbon atoms [92]. For the samples related to the Ultra-Turrax ball-milling, the same tendency is not verified, presenting an anomalous behavior regarding the $\mathrm{I}_{\mathrm{D}} / \mathrm{I}_{\mathrm{G}}$ ratio variation with changes in speed rotation.

The commercial graphite sample presents a similar $\mathrm{I}_{\mathrm{D}} / \mathrm{I}_{\mathrm{G}}$ ratio compared to that obtained by Labunov et al. (0.24) [93]; however, Dubale et al. [94] presented an increased value in the $\mathrm{I}_{\mathrm{D}} / \mathrm{I}_{\mathrm{G}}$ ratio of 1.31 , indicating that the studied graphite in this work presents fewer defects. The same authors presented the $\mathrm{I}_{\mathrm{D}} / \mathrm{I}_{\mathrm{G}}$ ratio of 0.403 for graphene, which is significantly higher than the graphene studied in this work.

\subsection{Electrochemical Behavior of G_REF and Commercial Graphite Modified Electrodes}

To establish reference values for the electrochemical performance of the different carbon materials, a systematic study was carried out using a three-electrode electrochemical cell and a working electrode modified with commercial graphene (G_REF) and commercial graphite thin films; the experimental characterization of the electrochemical properties of these systems are displayed in Figures 6 and 7, respectively.

Figures 6 and 7 a display the galvanostatic charge-discharge curves recorded with current densities 1,2 , and $4 \mathrm{~A} \cdot \mathrm{g}^{-1}$. At $1 \mathrm{~A} \cdot \mathrm{g}^{-1}$ the capacitance values obtained were $5.45 \mathrm{~F} \cdot \mathrm{g}^{-1}$ for G_REF/E200 and $4.27 \mathrm{~F} \cdot \mathrm{g}^{-1}$ for the commercial graphite, as displayed in Table 3.

From the analysis of Figures 6 and $7 \mathrm{~b}$ (scan rate evaluation at $30^{\circ} \mathrm{C}$ ) and Figures 6 and $7 \mathrm{c}$ (temperature effect), the G_REF system presents a rectangular shape in the cyclic voltammetric profile, showing almost ideal capacitance behavior, while the graphite-modified GC electrode does not follow that pattern. The scan rate effect in both carbon materials presents an increase in both anodic and cathodic current with the increase in the scan rate.

The temperature effect was studied for both G_REF and graphite immersed in E200, and the detailed results are presented in Figures 6 and $7 c-f$.

The gravimetric capacitance-potential curves (Figures 6 and 7c) for both G_REF and the graphite materials in E200 present a U-shape. Costa et al. [95] studied the electrochemical interfaces of DES-based on choline chloride mixtures with ethylene glycol, 1,2-propanediol, and urea at the $\mathrm{Hg}$ electrode, presenting similar U shapes for the studied DES. In this study, the material of the modified electrode does not present any effect, since it does not change the shape of the curves in terms of either the anodic or cathodic potentials.

Both G_REF/E200 and graphite/E200 show an increase in gravimetric capacitance with increasing temperature (Figures 6 and 7a). Even though there is a substantial drop in electrochemical performance in the initial cycles, the retention in capacitance starts to stabilize after 400 cycles for G_REF/E200 (Figure 6), and the stabilization does not occur for graphite/E200 for 1000 cycles. There is an inconsistency in the variation of the capacitance retention with temperature; however, it is possible to assume that the tendency is to decrease the capacitance retention by increasing temperature. This might be due to the deterioration of the carbon composite film present on the electrode's surface. 


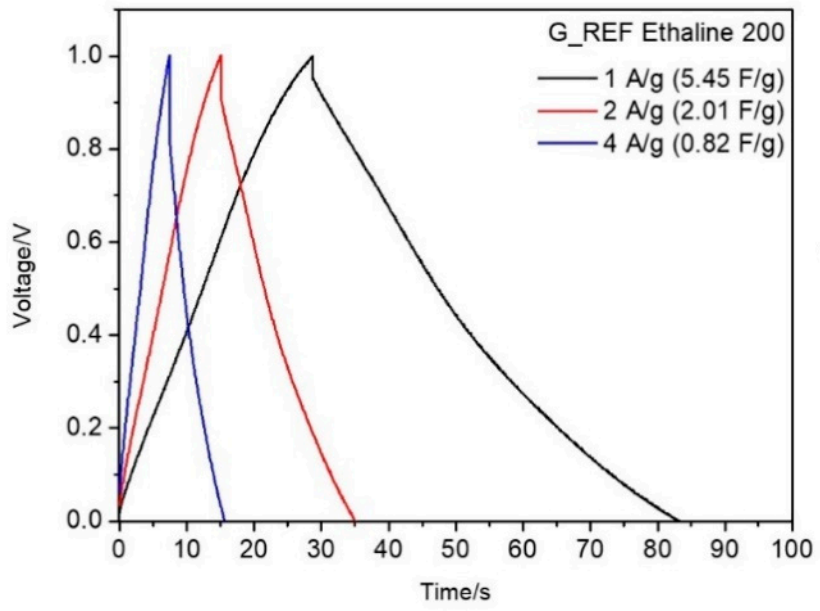

(a)

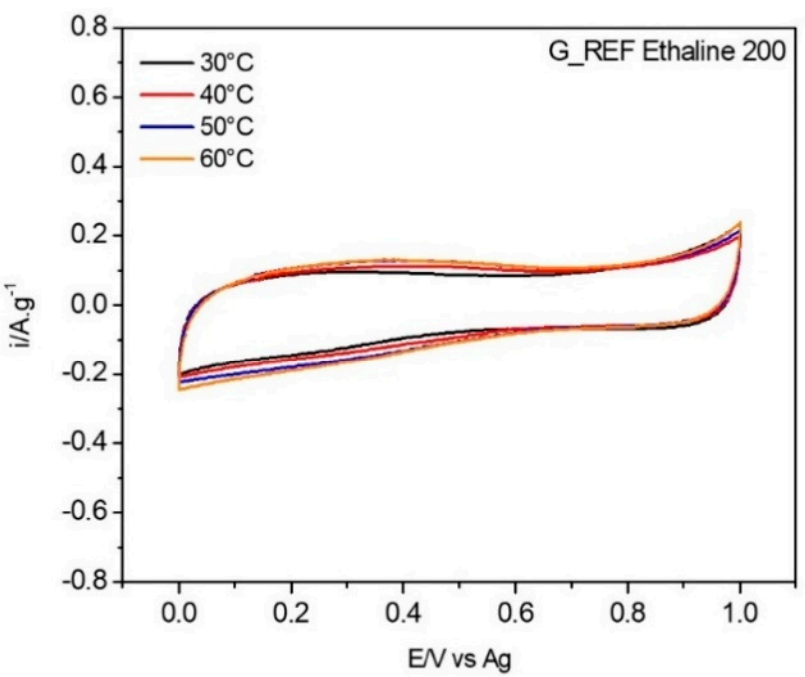

(c)

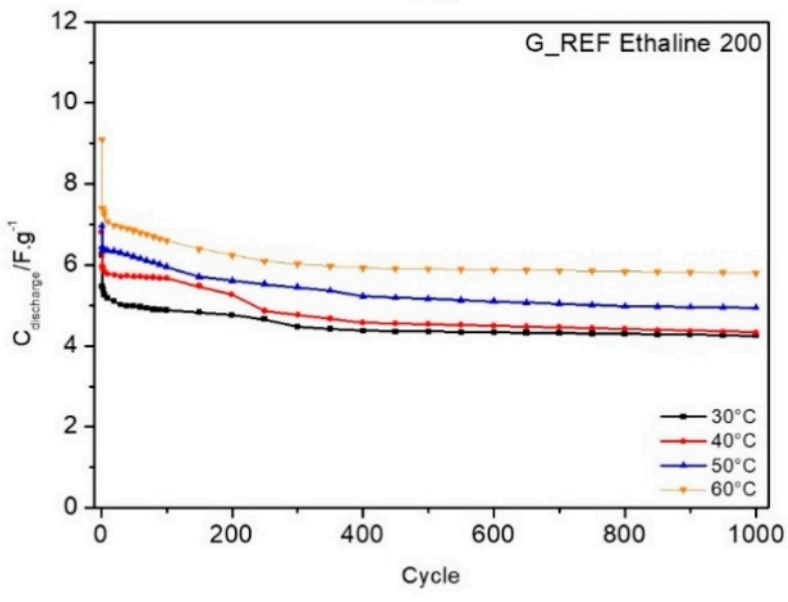

(e)

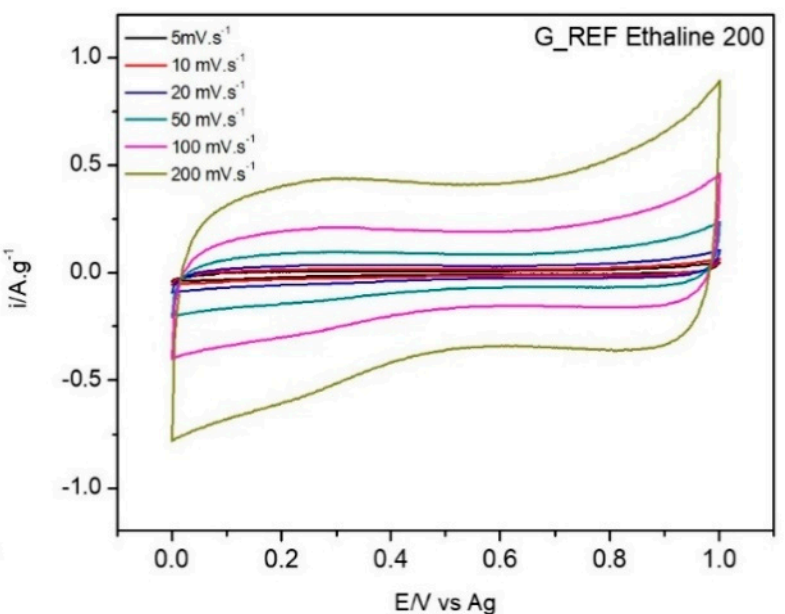

(b)

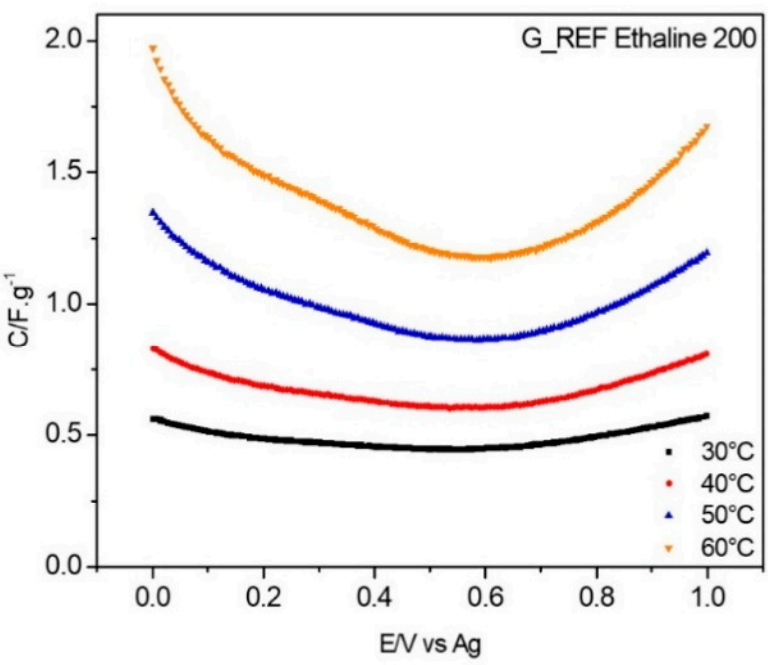

(d)

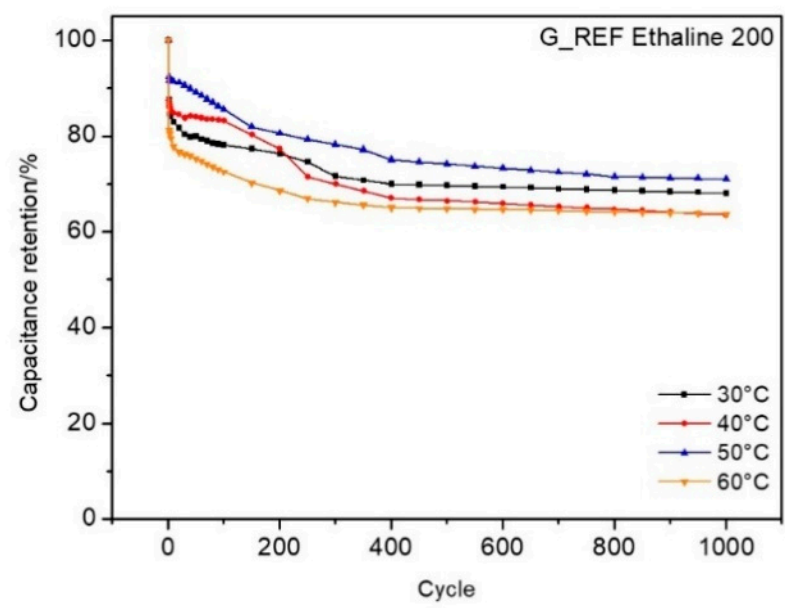

(f)

Figure 6. Electrochemical testing of G_REF in E200 electrolyte: (a) galvanostatic charge-discharge curves recorded with current density 1,2 and $4 \mathrm{~A} \cdot \mathrm{g}^{-1}$ at $30^{\circ} \mathrm{C}$; (b) CV curves recorded at scan rates 5, 10, 20, 50, 100 and $200 \mathrm{mV} \cdot \mathrm{s}^{-1}$ at $30{ }^{\circ} \mathrm{C}$, temperature effect on (c) cyclic voltammetry at $50 \mathrm{mV}^{-1}{ }^{-1}$; (d) capacitance-potential curve; (e) discharge gravimetric capacitance for 1000 cycles; and (f) capacitance retention. 


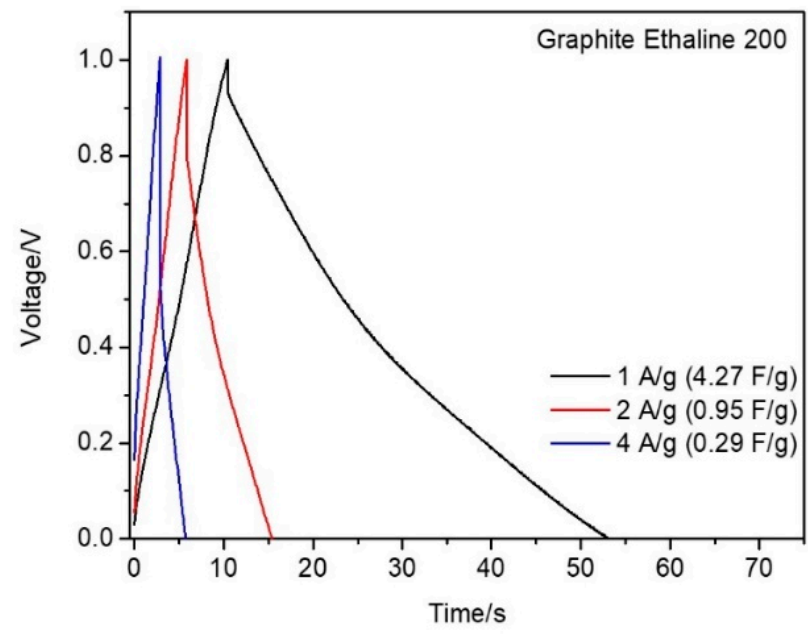

(a)

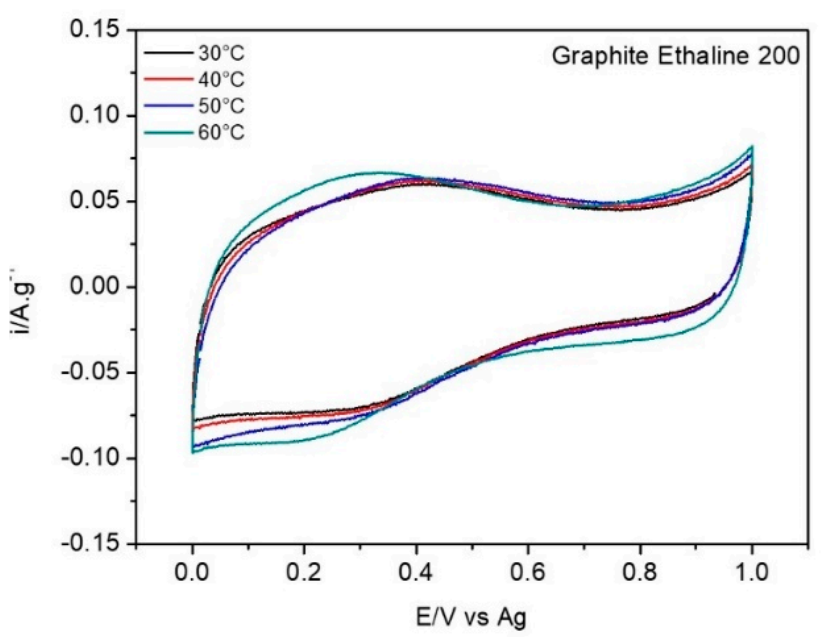

(c)

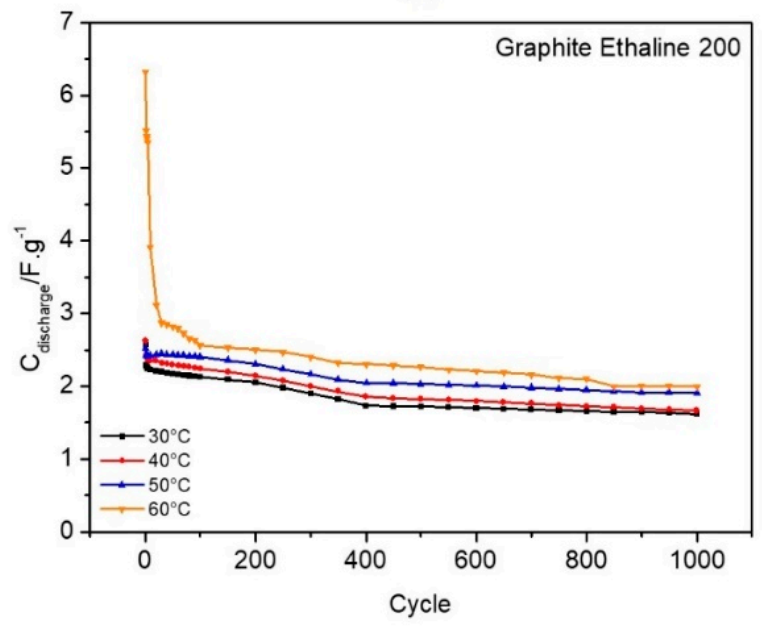

(e)

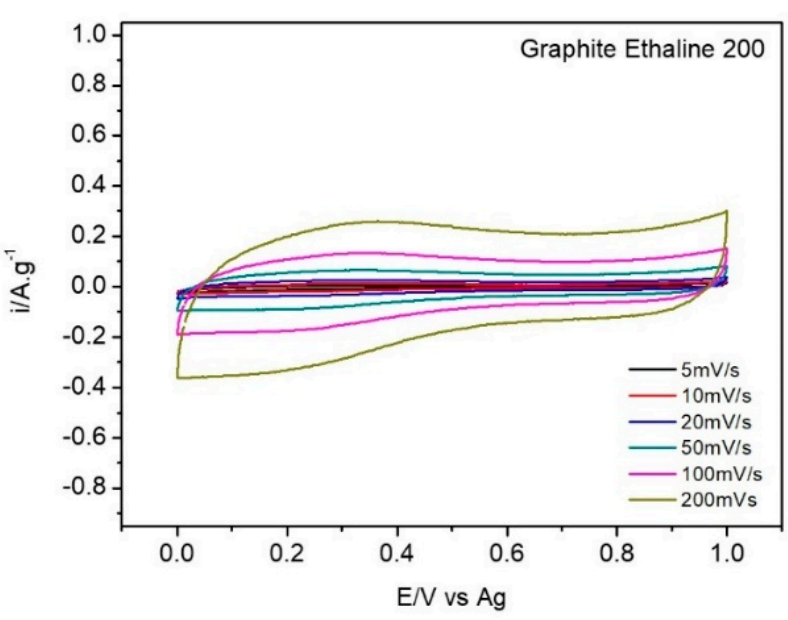

(b)

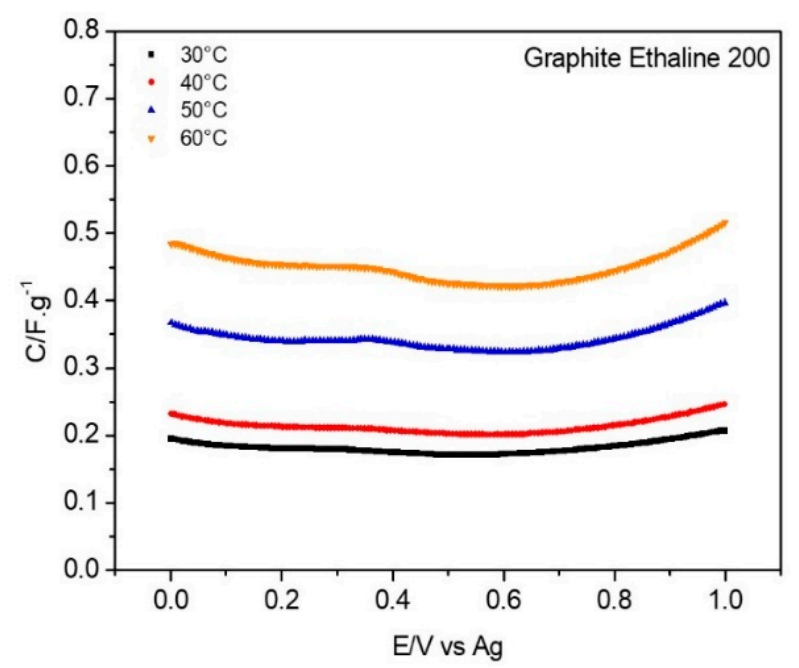

(d)

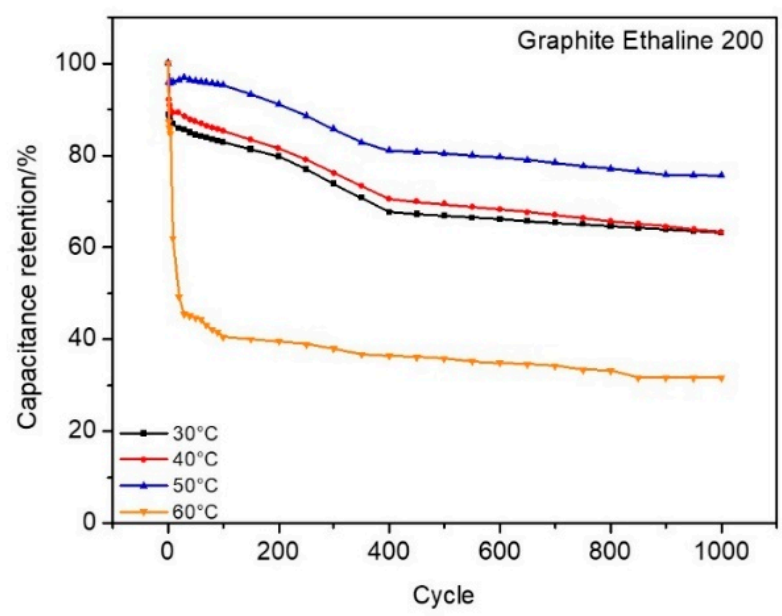

(f)

Figure 7. Electrochemical testing of commercial graphite in E200 electrolyte: (a) galvanostatic charge-discharge curves recorded with current density 1,2 and $4 \mathrm{~A} \cdot \mathrm{g}^{-1}$ at $30^{\circ} \mathrm{C}$; (b) CV curves recorded at scan rates 5, 10, 20, 50, 100 and $200 \mathrm{mV} . \mathrm{s}^{-1}$ at $30{ }^{\circ} \mathrm{C}$, temperature effect on $(\mathbf{c})$ cyclic voltammetry at $50 \mathrm{mV} \cdot \mathrm{s}^{-1} ;(\mathbf{d})$ capacitance-potential curve; (e) discharge gravimetric capacitance for 1000 cycles; and (f) capacitance retention. 


\subsection{Electrochemical Behavior of Ball-Milled Graphite Modified Electrodes}

Boosting the capacitance by increasing the interfacial area per volume has been the focus of scientific research for more efficient energy storage technologies aiming to increase supercapacitor energy [96].

Figure 8 illustrates the experimental results gathered in the electrochemical study regarding the effect of dry milling the graphite reference material for 10, 20, 40 and $60 \mathrm{~min}$ with the Retsch Mixer Mill MM400 equipment, compared to the G_REF sample at $30^{\circ} \mathrm{C}$. The ball-milling time effect was evaluated by cyclic voltammetry (Figure 8a), gravimetric potential curves (Figure $8 \mathrm{~b}$ ), galvanostatic charge-discharge curve profiles (Figure 8c), discharge gravimetric capacitance (Figure 8d), and capacitance retention (Figure 8e). The temperature effect on capacitance is presented in Table S2 (SI) for all ball-milled carbons for temperatures between $30^{\circ} \mathrm{C}$ and $60^{\circ} \mathrm{C}$.

Cyclic voltammograms (CV) obtained between 0 and $1 \mathrm{~V}$ measured at different interfacial composite surfaces immersed in E200 are shown in Figure 8a. The CV curves display the characteristic capacitor-like profile in the shape of almost rectangular cyclic behavior for the graphite prepared for 20 and $40 \mathrm{~min}$. The CV comparison also shows an abrupt decrease in current gravimetric density for the material prepared, using a longer interval (60 $\mathrm{min}$ ) for the ball milling process. This may result from a decrease in the penetration ability of the electrolyte ions to reach the inner spaces of pores induced by the applied potential. This behavior may also reflect the relationship established between the samples' milling time procedure and the ability of ions to more easily reach the pores under conditions of finely controlled microstructure.

The CVs do not show evidence of any pseudocapacitance (faradaic process) contribution, which may indicate that the gravimetric capacitance determined in this work is purely capacitive. The gravimetric capacitance (Figure $8 b$ ) increases with the increasing time of sample treatment, presenting higher values compared to G_REF for the G20 and G40 samples. These results agree with the changes reported in the BET study, indicating that the increase in both pore volume and specific surface area leads to an increase in gravimetric capacitance. The G40 ball-milled graphite with an approximate surface area of $308.6 \mathrm{~m}^{2} \cdot \mathrm{g}^{-1}$ presented the highest specific capacitance, with an approximate value of $25 \mathrm{~F} \cdot \mathrm{g}^{-1}$, four times greater than the commercial graphene sample (G_REF). An increase in surface area and pore volume leads to more surface sites that are available for charge storage. Several authors have studied the effects of surface area and pore volume on the specific capacitance of EDLCs, showing that there is an increase in capacitance with an increase of both parameters [97-99]. Eguchi et al. [100] studied the ball-milling effect on high-specific surface area activated carbon $\left(>3000 \mathrm{~m}^{2} \cdot \mathrm{g}^{-1}\right)$ manufactured from petroleum coke employing $\mathrm{KOH}$ activation with different ball-milling times, showing that prolonged milling led to a degeneration of pores and a decrease in both gravimetric specific capacitance and pore volume.

It is known that only the pore surface accessible by the ions can contribute to double-layer capacitance. The bigger the ions present in the electrolyte, the larger the pore size required for the carbon materials [101]. The benefits related to a high surface area need to be balanced by the associated loss of stability, in which a careful compromise needs to be taken into consideration. In this case, using DES as an electrolyte, pore size and surface area need to present higher values when compared to aqueous electrolytes.

This effect is reversed with the G60 sample, where the increase in milling time led to a substantial decrease in capacitance. A decrease in capacitance can be explained by the overlapping and agglomeration of graphite layers [61]. This phenomenon may be due to the van der Waals interactions that can occur between the graphene sheets [53]. 


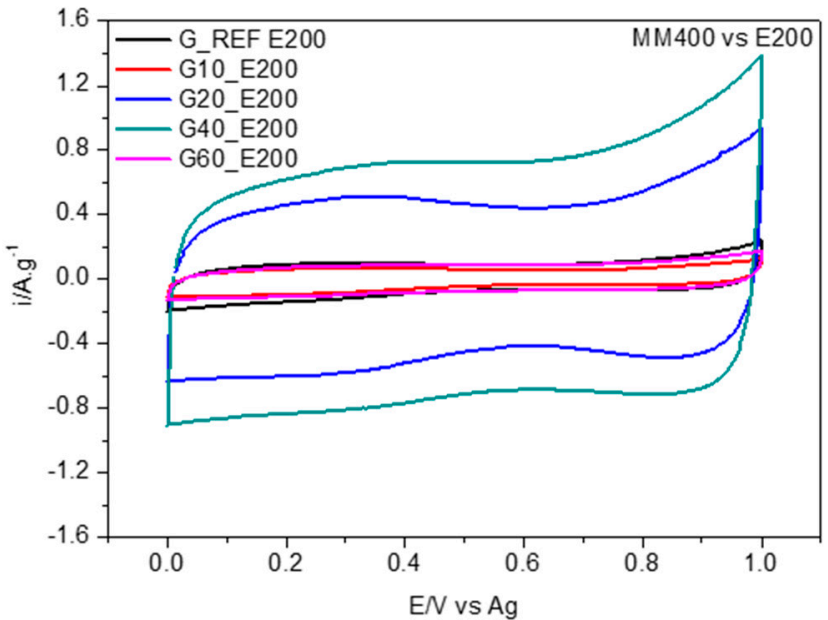

(a)

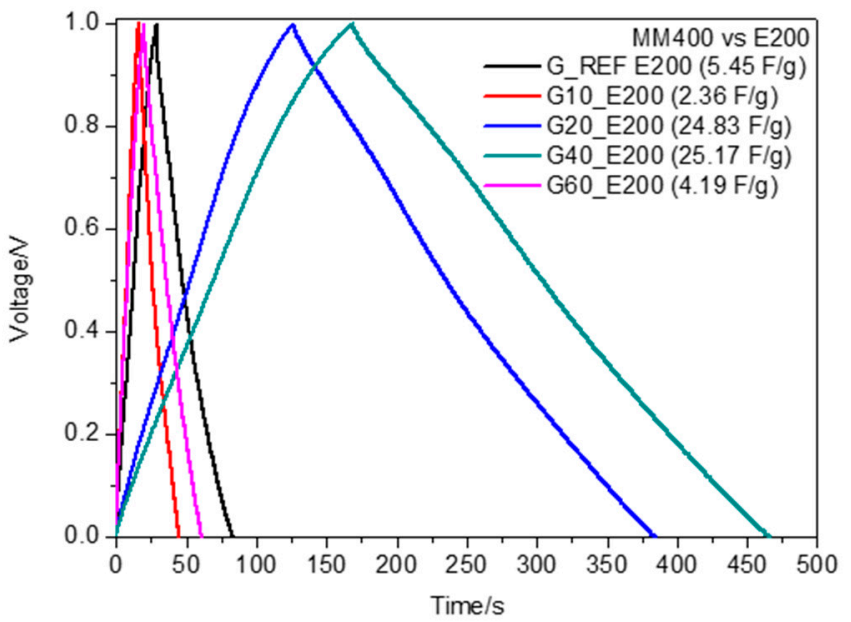

(c)

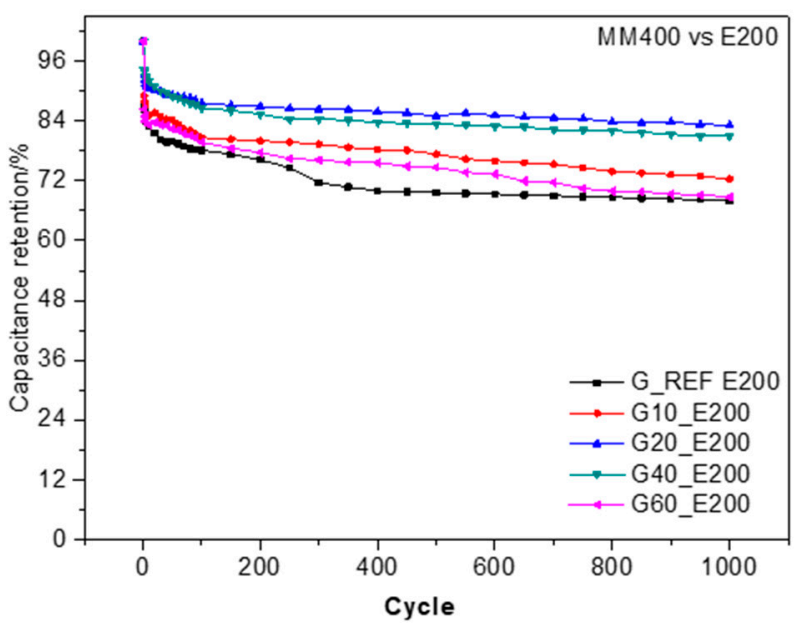

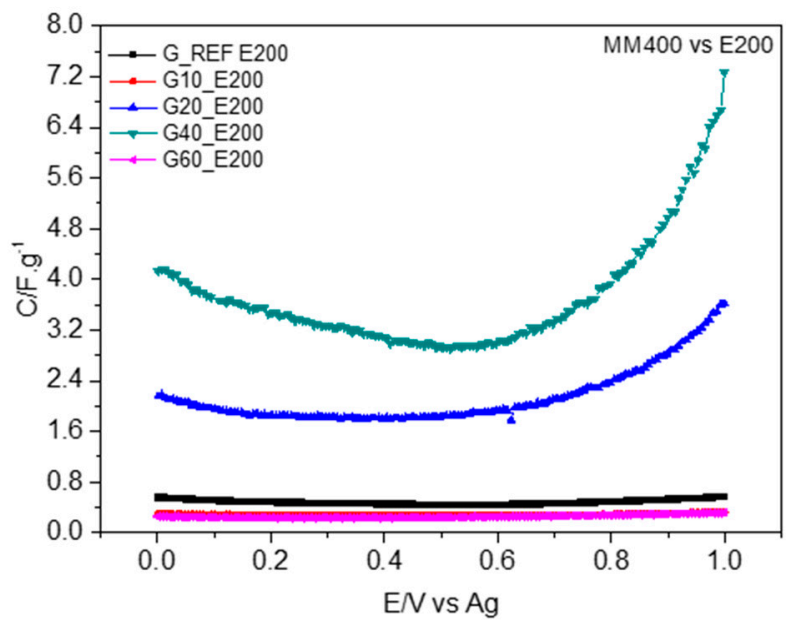

(b)

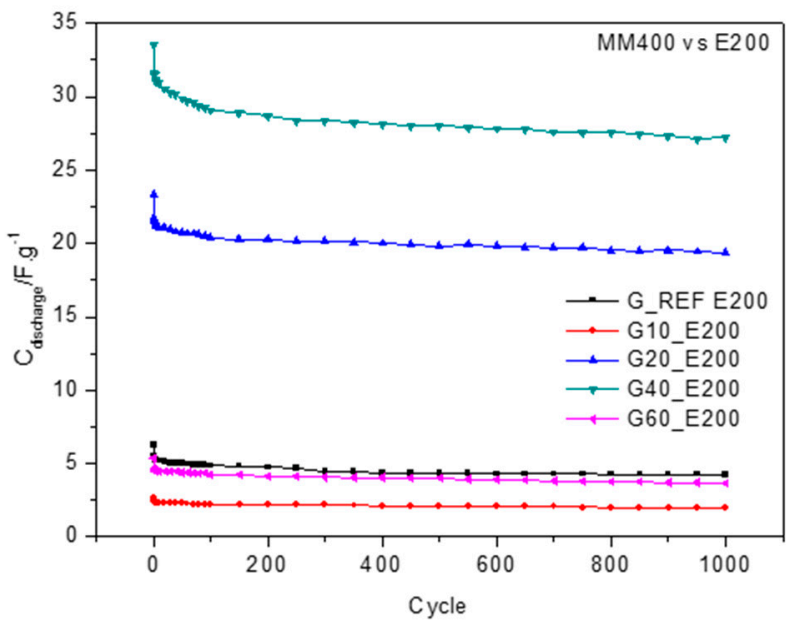

(d)

(e)

Figure 8. Ball milling effect using Retsch Mixer Mill MM400 for G_REF, G10, G20, G40, and G60 at $30{ }^{\circ} \mathrm{C}$ in E200. (a) cyclic voltammetry at scan rate of $50 \mathrm{mV} \cdot \mathrm{s}^{-1}$ at $30^{\circ} \mathrm{C}$; (b) capacitance-potential curve; (c) galvanostatic charge-discharge curves recorded with current density $1 \mathrm{~A} \cdot \mathrm{g}^{-1}$; (d) discharge gravimetric capacitance for 1000 cycles; (e) capacitance retention (at $\left.1 \mathrm{~A} \cdot \mathrm{g}^{-1}\right)$. 
A galvanostatic charge-discharge test was performed on the different graphitic materials/ethaline 200 interfaces to evaluate its capacitive behavior; the results obtained at current density $1 \mathrm{~A} \cdot \mathrm{g}^{-1}$ are displayed in Figure $8 \mathrm{c}$. For the G_REF and ball-milled samples (G10 and G60), the response of the interface approaches the ideal linear chargepotential relationship. For the G20 and G40 samples, the total charged interface initially drops, followed by a constant capacitive performance. A slight IR drop in the galvanostatic charge-discharge curves is more evident at the G20 and G40/ethaline 200 interfaces. Since IR drop is a direct measure of electrolyte resistance, influences the overall power performance, and has a significant impact on electrochemical measurements, these effects must be taken into consideration throughout the interpretation of electrochemical data.

The cycle rate performance of the specific capacitance was also evaluated from the charge-discharge cycles for 1000 cycles at a current density of $1 \mathrm{~A} \cdot \mathrm{g}^{-1}$ and is represented in Figure 8d.

These results point to excellent stability and reliability at these current charge/discharge cycles. After 1000 cycles, capacitance retention was as high as 80\% for the G20 and G40 samples (Figure 8e). The high specific capacitance $\left(25.10 \mathrm{~F} \cdot \mathrm{g}^{-1}\right.$ ) also results from the high pore volume $\left(0.03 \mathrm{~cm}^{3} \cdot \mathrm{g}^{-1}\right)$ and high surface area $\left(308.58 \mathrm{~F} \cdot \mathrm{g}^{-1}\right)$ of the $\mathrm{G} 40$ sample. Schutjajew et al. [102] recently studied the effects of the pore size and specific surface area of carbon materials in an ionic liquid electrolyte through cyclic voltammetry for supercapacitor applications. A clear correlation was found, showing that higher pore volume leads to higher peak areas and currents, with a specific surface area of $881 \mathrm{~m}^{2} \cdot \mathrm{g}^{-1}$ and pore volume of $0.123 \mathrm{~cm}^{3} \cdot \mathrm{g}^{-1}$ for the highest specific capacitance of $151.8 \mathrm{~F} \cdot \mathrm{g}^{-1}$ at a current density of $0.1 \mathrm{~A} \cdot \mathrm{g}^{-1}$.

For further comparison, a parallel study was performed for graphite powder ball-milled with cheaper equipment, the IKA ULTRA-TURRAX ${ }^{\circledR}$ Tube Drive ball miller; both morphological (SEM) and electrochemical studies are presented in SI (Figures S2 and S14, respectively). Other studies changing the milling time (30,40, and $50 \mathrm{~min}$ ) for sample G@6000 were performed, without observing significant changes (Figure S15 and Table S3, in SI). Thus, results for the samples G@2000 to G@6000 with 1h of milling were presented.

The electrochemical studies grafting the glassy carbon electrode with G@2000, G@3000, and G@6000 materials (Figure S14 in SI) show far less specific capacitance compared to the previously-reported ball-milled carbon materials (G10 to G40). Even commercial graphite electrochemically outperformed the material obtained by the ULTRA-TURRAX ${ }^{\circledR}$ method. This electrochemical performance is in line with the information obtained for the morphological data and shows that the ULTRA-TURRAX ${ }^{\circledR}$ method does not allow the required changes in the graphite, while longer times could not be used due to overheating during the process causing the plastic tube to rupture.

Both ball-milling methods present lower gravimetric capacitance compared with other studies performed using aqueous electrolytes. Zdolsek et al. [103] presented carbon materials synthesized by ionic liquids through hydrothermal carbonization, showing performances around $148 \mathrm{~F} \cdot \mathrm{g}^{-1}$ at $1 \mathrm{~A} \cdot \mathrm{g}^{-1}$, where the highest value obtained in this work is $25.17 \mathrm{~F} \cdot \mathrm{g}^{-1}$. The same happens in Iakunkov's work, in which the workgroup prepared rGO materials through ball milling and activation temperatures with a capacitance of $174 \mathrm{~F} \cdot \mathrm{g}^{-1}$ [104]. However, these results were obtained using two-electrode coin cells with higher electrode areas (around $1 \mathrm{~cm}^{2}$ ), and therefore it is not valid to make a direct comparison of the experimental data.

\section{Conclusions}

Commercial graphite was subjected to two dry ball milling methods, with the aim of evaluating the contribution of the physical treatment to the properties of the carbon materials. Assessment of the effectiveness of the dry ball-milling process was made through the capacitance measurement of glassy carbon composite electrodes, using E200 as an electrolyte. Further, the structural changes of the ball-milled and composite powders were characterized using BET and SEM analysis. Raman and ATR-FTIR were per- 
formed, demonstrating the changes in the characteristics of the different modified samples. Distinguishing features were obtained between the different ball-milled samples and commercial materials.

The optimal ball milling time was achieved at 40 min with the Retsch Mixer Mill MM400. G40 ball-milled graphite material presented the highest surface area $\left(308.6 \mathrm{~m}^{2} \cdot \mathrm{g}^{-1}\right)$, pore volume $\left(0.03163 \mathrm{~cm}^{3} \cdot \mathrm{g}^{-1}\right)$, and specific capacitance $\left(25 \mathrm{~F} \cdot \mathrm{g}^{-1}\right)$, four times higher than G_REF. The results obtained in the present study indicate that the increase in gravimetric capacitance is strongly related to the increase in porosity and surface area. For longer milling periods (G60 sample), the surface area decreased, as well as the gravimetric capacitance. The use of ULTRA-TURRAX ${ }^{\circledR}$ Tube Drive did not have a significant impact on the carbon material structure; $1 \mathrm{~h}$ of treatment at $4000 \mathrm{rpm}$ was equivalent to $10 \mathrm{~min}$ of treatment using the MM400 vibromachine. These results allowed to optimize the electrode capacitance by increasing the interfacial area per volume of carbon materials through an easy and sustainable method for further scaling up to a coin cell setup.

These results highlight the potential of using ball-milled graphite materials to develop a new generation of sustainable and environmentally-friendly carbon-based materials, with potential applications in advanced storage devices such as high-energy supercapacitors using deep eutectic solvents.

Supplementary Materials: The following are available online at https:/ /www.mdpi.com/article/10 .3390/nano11123258/s1: Figure S1: Electron microscopy images showing the structure of G_REF (A) and commercial graphite (B) samples with $5000 \times$ (a), 10,000 $\times$ (b) magnification; Figure S2: Electron microscopy images showing the structure of G@2000, G@4000 and G@6000 sample with 5000× (a), $10,000 \times$ (b) magnification; Figure S3: AFM topography images of samples G10 to G60 in GC substrate at $50 \mu \mathrm{m} \times 50 \mu \mathrm{m}$ (a) and $10 \mu \mathrm{m} \times 10 \mu \mathrm{m}$ (b) resolution; Figure S4: Surface roughness (Ra) obtained from the AFM images for Samples G10 to G60, at $50 \mu \mathrm{m} \times 50 \mu \mathrm{m}$ resolution; Figure S5: Raman spectra of G_REF (a) and the deconvolution of the peaks from the 1st order Raman region of the signal emitted by G_REF (b). The sum of the deconvolution is marked with yellow line; Figure S6: Raman spectra of graphite (a) and the deconvolution of the peaks from the first order Raman region of the signal emitted by graphite (b). The sum of the deconvolution is marked with yellow line; Figure S7: Raman spectra of G10 sample (a) and the deconvolution of the peaks from the first order Raman region of the signal emitted by G10 sample (b). The sum of the deconvolution is marked with yellow line; Figure S8: Raman spectra of G20 sample (a) and the deconvolution of the peaks from the first order Raman region of the signal emitted by G20 sample (b). The sum of the deconvolution is marked with yellow line; Figure S9: Raman spectra of G40 sample (a) and the deconvolution of the peaks from the first order Raman region of the signal emitted by G40 sample (b). The sum of the deconvolution is marked with yellow line; Figure S10: Raman spectra of G60 sample (a) and the deconvolution of the peaks from the first order Raman region of the signal emitted by G60 sample (b). The sum of the deconvolution is marked with yellow line; Figure S11: Raman spectra of G@2000 sample (a) and the deconvolution of the peaks from the first order Raman region of the signal emitted by G@2000 sample (b). The sum of the deconvolution is marked with yellow line; Figure S12: Raman spectra of G@4000 sample (a) and the deconvolution of the peaks from the first order Raman region of the signal emitted by G@4000 sample (b). The sum of the deconvolution is marked with yellow line; Figure S13: Raman spectra of G@6000 sample (a) and the deconvolution of the peaks from the 1st order Raman region of the signal emitted by G@6000 sample (b). The sum of the deconvolution is marked with yellow line; Figure S14: Ball milling effect using IKA ULTRA-TURRAX@Tube Drive for G_REF, G@2000, G@4000 and G@6000 at $30{ }^{\circ} \mathrm{C}$, with comparison with G40 sample. (a) cyclic voltammetry; (b) galvanostatic charge-discharge curves recorded with current density $1 \mathrm{~A} \cdot \mathrm{g}^{-1}$; (c) discharge gravimetric capacitance for 1000 cycles; d) capacitance retention; Figure S15: Ball milling time effect using IKA ULTRA-TURRAX®Tube Drive for G_REF G@6000 at $30{ }^{\circ} \mathrm{C}$. (a) galvanostatic charge-discharge curves recorded with current density $1 \mathrm{~A}^{-1} \mathrm{~g}^{-1}$; (b) capacitance retention for 1000 cycles; Table S1: Raman data related to the G and D bands locations and ID/IG ratio for all the studied carbon materials; Table S2: Temperature effect on capacitance for the different ball-milled carbon materials; Table S3: specific capacitance determined for IKA ULTRA-TURRAX ${ }^{\circledR}$ Tube Drive G@6000 with different milling time (30, 40, 50 and $60 \mathrm{~min})$. 
Author Contributions: Conceptualization, A.T.S.C.B. and C.M.P.; Methodology, A.T.S.C.B., R.C. and C.M.P.; Formal analysis, A.T.S.C.B. and C.M.P.; Investigation, A.T.S.C.B. and C.M.P.; Writing-original draft, A.T.S.C.B. and C.M.P.; Writing-review \& editing, A.T.S.C.B., R.C. and C.M.P.; Supervision, A.F.S. and C.M.P.; Resources, C.M.P.; Funding acquisition, C.M.P. All authors have read and agreed to the published version of the manuscript.

Funding: This work was financially supported by the FCT under Research Grant UIDB/00081/2020 CIQUP and IL4Energy project (02/SAICT/2017-NORTE-01-0145-FEDER-032294) funded by FCT and the European Funds for regional development (FEDER) through the operational program of competitiveness and internationalization with reference POCI-01-0145-FEDER-032294). Ana Brandão thank SCANSCI-equipamentos de laboratório for the financial support given to the PhD program and the scholarship awarded by FCT with reference 2021.04783.BD. Renata Costa thank FCT for funding (SFRH/BPD/89752/2012) under the QREN-POPH-Advanced Training, subsidized by European Union and national MEC funds.

Institutional Review Board Statement: Not applicable.

Informed Consent Statement: Not applicable.

Data Availability Statement: Not applicable.

Acknowledgments: The authors would like to thank the COST Action CA15107-MULTICOMP (MULTI-FUNCTIONAL NANO-CARBON COMPOSITE MATERIALS NETWORK).

Conflicts of Interest: The authors declare no conflict of interest.

\section{References}

1. Ratajczak, P.; Suss, M.E.; Kaasik, F.; Béguin, F. Carbon electrodes for capacitive technologies. Energy Storage Mater. 2019, 16, 126-145. [CrossRef]

2. Pareek, A.; Shanthi Sravan, J.; Venkata Mohan, S. Exploring chemically reduced graphene oxide electrode for power generation in microbial fuel cell. Mater. Sci. Energy Technol. 2019, 2, 600-606. [CrossRef]

3. Shin, D.; Lee, K.; Chang, N. Fuel economy analysis of fuel cell and supercapacitor hybrid systems. Int. J. Hydrog. Energy 2016, 41, 1381-1390. [CrossRef]

4. Iqbal, M.Z.; Siddique, S.; Khan, A.; Haider, S.S.; Khalid, M. Recent developments in graphene based novel structures for efficient and durable fuel cells. Mater. Res. Bull. 2019, 122, 110674. [CrossRef]

5. Iro, Z.S.; Subramani, C.; Dash, S.S. A brief review on electrode materials for supercapacitor. Int. J. Electrochem. Sci. 2016, 11, 10628-10643. [CrossRef]

6. Eftekhari, A. On the mechanism of microporous carbon supercapacitors. Mater. Today Chem. 2018, 7, 1-4. [CrossRef]

7. Yang, Z.; Tian, J.; Yin, Z.; Cui, C.; Qian, W.; Wei, F. Carbon nanotube- and graphene-based nanomaterials and applications in high-voltage supercapacitor: A review. Carbon N. Y. 2019, 141, 467-480. [CrossRef]

8. Ge, J.; Zhang, Y.; Heo, Y.-J.; Park, S.-J. Advanced Design and Synthesis of Composite Photocatalysts for the Remediation of Wastewater: A Review. Catal. 2019, 9, 122. [CrossRef]

9. Laskar, M.A.; Siddiqui, S. Chapter 12-Nanomaterials—based on graphene oxide and its derivatives-for separation and preconcentration of metal ions. In Micro and Nano Technologies; Elsevier: Amsterdam, The Netherlands, 2019; pp. 205-219, ISBN 978-0-12-815811-1.

10. Lin, Z.; Goikolea, E.; Balducci, A.; Naoi, K.; Taberna, P.L.; Salanne, M.; Yushin, G.; Simon, P. Materials for supercapacitors: When Li-ion battery power is not enough. Mater. Today 2018, 21, 419-436. [CrossRef]

11. Frackowiak, E.F.B.; Frackowiak, E. Carbon Materials for the Electrochemical Storage of Energy in capacitors. J. Carbon 2001, 39 , 937-950. [CrossRef]

12. Frackowiak, E. Supercapacitors based on carbon materials and ionic liquids. J. Braz. Chem. Soc. 2006, 17, 1074-1082. [CrossRef]

13. Frackowiak, E.; Abbas, Q.; Béguin, F. Carbon/carbon supercapacitors. J. Energy Chem. 2013, 22, 226-240. [CrossRef]

14. Béguin, F.; Presser, V.; Balducci, A.; Frackowiak, E. Carbons and electrolytes for advanced supercapacitors. Adv. Mater. 2014, 26, 2219-2251. [CrossRef]

15. Gu, W.; Yushin, G. Review of nanostructured carbon materials for electrochemical capacitor applications: Advantages and limitations of activated carbon, carbide-derived carbon, zeolite-templated carbon, carbon aerogels, carbon nanotubes, onion-like carbon, and graphene. Wiley Interdiscip. Rev. Energy Environ. 2014, 3, 424-473. [CrossRef]

16. Gorska, B.; Frackowiak, E.; Beguin, F. Redox active electrolytes in carbon/carbon electrochemical capacitors. Curr. Opin. Electrochem. 2018, 9, 95-105. [CrossRef]

17. Heidarinejad, Z.; Dehghani, M.H.; Heidari, M.; Javedan, G.; Ali, I.; Sillanpää, M. Methods for preparation and activation of activated carbon: A review. Environ. Chem. Lett. 2020, 18, 393-415. [CrossRef]

18. Zhang, L.; Chen, L.; Liu, J.; Fang, X.; Zhang, Z. Effect of morphology of carbon nanomaterials on thermo-physical characteristics, optical properties and photo-thermal conversion performance of nanofluids. Renew. Energy 2016, 99, 888-897. [CrossRef] 
19. Vivekchand, S.R.C.; Rout, C.S.; Subrahmanyam, K.S.; Govindaraj, A.; Rao, C.N.R. Graphene-based electrochemical supercapacitors. J. Chem. Sci. 2008, 120, 9-13. [CrossRef]

20. Sato, K.; Saito, R.; Oyama, Y.; Jiang, J.; Cançado, L.G.; Pimenta, M.A.; Jorio, A.; Samsonidze, G.G.; Dresselhaus, G.; Dresselhaus, M.S. D-band Raman intensity of graphitic materials as a function of laser energy and crystallite size. Chem. Phys. Lett. 2006, 427, 117-121. [CrossRef]

21. Wang, M.; Zhang, C.; Yan, S.; Chen, T.; Fang, H.; Yuan, X. Wide-Field Super-Resolved Raman Imaging of Carbon Materials. ACS Photonics 2021, 8, 1801-1809. [CrossRef]

22. Malka, D.; Berke, B.A.; Tischler, Y. Improving Raman spectra of pure silicon using super-resolved method. J. Opt. 2019, $21,075801$. [CrossRef]

23. Malka, D.; Berkovic, G.; Hammer, Y.; Zalevsky, Z. Super-resolved Raman spectroscopy. Spectrosc. Lett. 2013, 46, 307-313. [CrossRef]

24. Liu, W.-W.; Chai, S.-P.; Mohamed, A.R.; Hashim, U. Synthesis and characterization of graphene and carbon nanotubes: A review on the past and recent developments. J. Ind. Eng. Chem. 2014, 20, 1171-1185. [CrossRef]

25. Mohanpuria, P.; Rana, N.K.; Yadav, S.K. Biosynthesis of nanoparticles: Technological concepts and future applications. J. Nanoparticle Res. 2008, 10, 507-517. [CrossRef]

26. Fan, X.; Chang, D.W.; Chen, X.; Baek, J.-B.; Dai, L. Functionalized graphene nanoplatelets from ball milling for energy applications. Curr. Opin. Chem. Eng. 2016, 11, 52-58. [CrossRef]

27. Moreno-Fernández, G.; Boulanger, N.; Nordenström, A.; Iakunkov, A.; Talyzin, A.; Carriazo, D.; Mysyk, R. Ball-milling-enhanced capacitive charge storage of activated graphene in aqueous, organic and ionic liquid electrolytes. Electrochim. Acta 2021, 370. [CrossRef]

28. Godse, L.S.; Karandikar, P.B.; Khaladkar, M.Y. Study of carbon materials and effect of its ball milling, on capacitance of supercapacitor. Energy Procedia 2014, 54, 302-309. [CrossRef]

29. Nandhini, R.; Mini, P.A.; Avinash, B.; Nair, S.V.; Subramanian, K.R. V Supercapacitor electrodes using nanoscale activated carbon from graphite by ball milling. Mater. Lett. 2012, 87, 165-168. [CrossRef]

30. Dong, Y.; Zhang, S.; Du, X.; Hong, S.; Zhao, S.; Chen, Y.; Chen, X.; Song, H. Boosting the Electrical Double-Layer Capacitance of Graphene by Self-Doped Defects through Ball-Milling. Adv. Funct. Mater. 2019, 29, 1901127. [CrossRef]

31. Jiang, Y.; Ji, J.; Huang, L.; He, C.; Zhang, J.; Wang, X.; Yang, Y. One-pot mechanochemical exfoliation of graphite and in situ polymerization of aniline for the production of graphene/polyaniline composites for high-performance supercapacitors. RSC Adv. 2020, 10, 44688-44698. [CrossRef]

32. Jiang, L.; Yan, J.; Zhou, Y.; Hao, L.; Xue, R.; Jiang, L.; Yi, B. Activated carbon/graphene composites with high-rate performance as electrode materials for electrochemical capacitors. J. Solid State Electrochem. 2013, 17, 2949-2958. [CrossRef]

33. Chen, Z.; Ludwig, M.; Warr, G.G.; Atkin, R. Effect of cation alkyl chain length on surface forces and physical properties in deep eutectic solvents. J. Colloid Interface Sci. 2017, 494, 373-379. [CrossRef]

34. Pal, P.; Ghosh, A. Solid-state gel polymer electrolytes based on ionic liquids containing imidazolium cations and tetrafluoroborate anions for electrochemical double layer capacitors: Influence of cations size and viscosity of ionic liquids. J. Power Sources 2018, 406, 128-140. [CrossRef]

35. Zarrougui, R.; Hachicha, R.; Rjab, R.; Ghodbane, O. 1-Allyl-3-methylimidazolium-based ionic liquids employed as suitable electrolytes for high energy density supercapacitors based on graphene nanosheets electrodes. J. Mol. Liq. 2018, 249, 795-804. [CrossRef]

36. Jänes, A.; Permann, L.; Arulepp, M.; Lust, E. Electrochemical characteristics of nanoporous carbide-derived carbon materials in non-aqueous electrolyte solutions. Electrochem. Commun. 2004, 6, 313-318. [CrossRef]

37. Ma, K.; Zhang, C.; Woodward, C.E.; Wang, X. Bridging the gap between macroscopic electrochemical measurements and microscopic molecular dynamic simulations: Porous carbon supercapacitor with ionic liquids. Electrochim. Acta 2018, 289, 29-38. [CrossRef]

38. Watanabe, M.; Thomas, M.L.; Zhang, S.; Ueno, K.; Yasuda, T.; Dokko, K. Application of Ionic Liquids to Energy Storage and Conversion Materials and Devices. Chem. Rev. 2017, 117, 7190-7239. [CrossRef]

39. Martins, V.L.; Rennie, A.J.R.; Sanchez-Ramirez, N.; Torresi, R.M.; Hall, P.J. Improved Performance of Ionic Liquid Supercapacitors by using Tetracyanoborate Anions. ChemElectroChem 2018, 5, 598-604. [CrossRef]

40. Pandey, G.P.; Hashmi, S.A. Studies on electrical double layer capacitor with a low-viscosity ionic liquid 1-ethyl-3methylimidazolium tetracyanoborate as electrolyte. Bull. Mater. Sci. 2013, 36, 729-733. [CrossRef]

41. Laheäär, A.; Arenillas, A.; Béguin, F. Change of self-discharge mechanism as a fast tool for estimating long-term stability of ionic liquid based supercapacitors. J. Power Sources 2018, 396, 220-229. [CrossRef]

42. Timperman, L.; Vigeant, A.; Anouti, M. Eutectic mixture of Protic Ionic Liquids as an Electrolyte for Activated Carbon-Based Supercapacitors. Electrochim. Acta 2015, 155, 164-173. [CrossRef]

43. Tuhania, P.; Singh, P.K.; Bhattacharya, B.; Dhapola, P.S. PVDF-HFP and 1-ethyl-3-methylimidazolium thiocyanate-Doped polymer electrolyte for efficient supercapacitors. High Perform. Polym. 2018, 30, 911-917. [CrossRef]

44. David, M. Applications of Ionic Liquids in Polymer Science and Technology, 1st ed.; Springer: Berlin/Heidelberg, Germany, 2015; pp. 23-45, ISBN 9783662449035. 
45. Smith, E.L.; Abbott, A.P.; Ryder, K.S. Deep Eutectic Solvents (DESs) and Their Applications. Chem. Rev. 2014, 114, 11060-11082. [CrossRef] [PubMed]

46. Eftekhari, A. Supercapacitors utilising ionic liquids. Energy Storage Mater. 2017, 9, 47-69. [CrossRef]

47. Lee, Y.R.; Row, K.H. Comparison of ionic liquids and deep eutectic solvents as additives for the ultrasonic extraction of astaxanthin from marine plants. J. Ind. Eng. Chem. 2016, 39, 87-92. [CrossRef]

48. Khandelwal, S.; Tailor, Y.K.; Kumar, M. Deep eutectic solvents (DESs) as eco-friendly and sustainable solvent/catalyst systems in organic transformations. J. Mol. Liq. 2016, 215, 345-386. [CrossRef]

49. Abbott, A.P.; Ballantyne, A.; Harris, R.C.; Juma, J.A.; Ryder, K.S.; Forrest, G. A Comparative Study of Nickel Electrodeposition Using Deep Eutectic Solvents and Aqueous Solutions. Electrochim. Acta 2015, 176, 718-726. [CrossRef]

50. Abbott, A.P.; Al-Barzinjy, A.A.; Abbott, P.D.; Frisch, G.; Harris, R.C.; Hartley, J.; Ryder, K.S. Speciation, physical and electrolytic properties of eutectic mixtures based on $\mathrm{CrCl}_{3} \cdot 6 \mathrm{H}_{2} \mathrm{O}$ and urea. Phys. Chem. Chem. Phys. 2014, 16, 9047-9055. [CrossRef]

51. Abbott, A.; Aldous, L.; Borisenko, N.; Coles, S.; Fontaine, O.; Gamarra Garcia, J.D.; Gardas, R.; Hammond, O.; Hardwick, L.J.; Haumesser, P.H.; et al. Electrochemistry: General discussion. Faraday Discuss. 2018, 206, 405-426. [CrossRef] [PubMed]

52. Salomé, S.; Pereira, N.M.; Ferreira, E.S.; Pereira, C.M.; Silva, A.F. Tin electrodeposition from choline chloride based solvent: Influence of the hydrogen bond donors. J. Electroanal. Chem. 2013, 703, 80-87. [CrossRef]

53. Costa, R.; Pereira, C.M.; Silva, A.F. Insight on the effect of surface modification by carbon materials on the Ionic Liquid Electric Double Layer Charge Storage properties. Electrochim. Acta 2015, 176, 880-886. [CrossRef]

54. Sopcic, S.; Kraljic Rokovic, M.; Mandic, Z. Preparation and characterization of $\mathrm{RuO}_{2} /$ polyaniline/polymer binder composite electrodes for supercapacitor application. J. Electrochem. Sci. Eng. 2012, 2, 41-52. [CrossRef]

55. López-Chavéz, R.; Cuentas-Gallegos, A.K. The Effect of Binder in Electrode Materials for Capacitance Improvement and The Effect of Binder in Electrode Materials for Capacitance Improvement and EDLC Binder-free Cell Design. J. New Mater. Electrochem. Syst. 2013, 16, 139-251.

56. Silva, F.; Gomes, C.; Figueiredo, M.; Costa, R.; Martins, A.; Pereira, C.M. The electrical double layer at the [BMIM][PF6] ionic liquid/electrode interface-Effect of temperature on the differential capacitance. J. Electroanal. Chem. 2008, 622, 153-160. [CrossRef]

57. Stoller, M.D.; Ruoff, R.S. Best practice methods for determining an electrode material's performance for ultracapacitors. Energy Environ. Sci. 2010, 3, 1294-1301. [CrossRef]

58. De Oliveira, R.R.L.; Albuquerque, D.A.C.; Cruz, T.G.S. Measurement of the Nanoscale Roughness by Atomic Force Microscopy: Basic Principles and Applications. Available online: https:/ /www.intechopen.com/chapters/33450 (accessed on 10 September 2021).

59. Ghosh, A.; Subrahmanyam, K.S.; Krishna, K.S.; Datta, S.; Govindaraj, A.; Pati, S.K.; Rao, C.N.R. Uptake of $\mathrm{H}_{2}$ and CO $\mathrm{CO}_{2}$ by Graphene. J. Phys. Chem. C 2008, 112, 15704-15707. [CrossRef]

60. Wasalathilake, K.C.; Ayoko, G.; Yan, C. Porous Graphene Materials for Energy Storage and Conversion Applications. Recent Adv. Graphene Res. 2016, 2, 196.

61. Bourlinos, A.B.; Steriotis, T.A.; Karakassides, M.; Sanakis, Y.; Tzitzios, V.; Trapalis, C.; Kouvelos, E.; Stubos, A. Synthesis, characterization and gas sorption properties of a molecularly-derived graphite oxide-like foam. Carbon N. Y. 2007, 45, 852-857. [CrossRef]

62. Disma, F. Effect of Mechanical Grinding on the Lithium Intercalation Process in Graphites and Soft Carbons. J. Electrochem. Soc. 1996, 143, 3959. [CrossRef]

63. Welham, N.J.; Williams, J.S. Extended milling of graphite and activated carbon. Carbon N. Y. 1998, 36, 1309-1315. [CrossRef]

64. Chen, Y.; Fitz Gerald, J.; Chadderton, L.T.; Chaffron, L. Nanoporous carbon produced by ball milling. Appl. Phys. Lett. 1999, 74, 2782-2784. [CrossRef]

65. Zhang, L.; Zhang, R.; Zhan, L.; Qiao, W.; Liang, X.; Ling, L. Effect of ball-milling technology on pore structure and electrochemical properties of activated carbon. J. Shanghai Univ. Engl. Ed. 2008, 12, 372-376. [CrossRef]

66. Mhadhbi, M. Modelling of the High-Energy Ball Milling Process. Adv. Mater. Phys. Chem. 2021, 11, 31-44. [CrossRef]

67. Xing, T.; Li, L.H.; Hou, L.; Hu, X.; Zhou, S.; Peter, R.; Petravic, M.; Chen, Y. Disorder in ball-milled graphite revealed by Raman spectroscopy. Carbon N. Y. 2013, 57, 515-519. [CrossRef]

68. Zhao, Y.-P.; Wang, G.-C.; Lu, T.-M.; Palasantzas, G.; De Hosson, J.T.M. Surface-roughness effect on capacitance and leakage current of an insulating film. Phys. Rev. B 1999, 60, 9157-9164. [CrossRef]

69. Palasantzas, G.; De Hosson, J.T.M. The effect of mound roughness on the electrical capacitance of a thin insulating film. Solid State Commun. 2001, 118, 203-206. [CrossRef]

70. Patrikar, R.M.; Dong, C.Y.; Zhuang, W. Modelling interconnects with surface roughness. Microelectron. J. 2002, 33, 929-934. [CrossRef]

71. Ţucureanu, V.; Matei, A.; Avram, A.M. FTIR Spectroscopy for Carbon Family Study. Crit. Rev. Anal. Chem. 2016, 46, 502-520. [CrossRef] [PubMed]

72. Breeding, C.; Shigley, J. The "type" classification system of diamonds and its importance in gemology. Gems Gemol. 2009, 45, 96-111. [CrossRef]

73. Dovbeshko, G.I.; Chegel, V.I.; Gridina, N.Y.; Repnytska, O.P.; Shirshov, Y.M.; Tryndiak, V.P.; Todor, I.M.; Solyanik, G.I. Surface enhanced IR absorption of nucleic acids from tumor cells: FTIR reflectance study. Biopolym. Biospectroscopy Sect. 2002, 67, 470-486. [CrossRef] 
74. Schulz, H.; Baranska, M. Identification and quantification of valuable plant substances by IR and Raman spectroscopy. Vib. Spectrosc. 2007, 43, 13-25. [CrossRef]

75. Nicolaisen, F.M. IR absorption spectrum $\left(4200-3100 \mathrm{~cm}^{-1}\right)$ of $\mathrm{H}_{2} \mathrm{O}$ and $\left(\mathrm{H}_{2} \mathrm{O}\right)_{2}$ in $\mathrm{CCl}_{4}$. Estimates of the equilibrium constant and evidence that the atmospheric water absorption continuum is due to the water dimer. J. Quant. Spectrosc. Radiat. Transf. 2009, 110, 2060-2076. [CrossRef]

76. Huang, B.; Wang, Q.; Li, Y.; Zhang, M.; Wei, X. Preparation and characterisation of graphene. Mater. Res. Innov. 2015, 19, S9344-S9350. [CrossRef]

77. Çiplak, Z.; Yildiz, N.; Calimli, A. Investigation of graphene/Ag nanocomposites synthesis parameters for two different synthesis methods. Fuller. Nanotub. Carbon Nanostructures 2015, 23, 361-370. [CrossRef]

78. Coates, J. Encyclopedia of Analytical Chemistry-IInterpretation of Infrared Spectra, A Practical Approach. Encycl. Anal. Chem. 2004, 1, 23.

79. Wang, X.; Christopher, J.W.; Swan, A.K. 2D Raman band splitting in graphene: Charge screening and lifting of the K-point Kohn anomaly. Sci. Rep. 2017, 7, 13539. [CrossRef] [PubMed]

80. Ferrari, A.C.; Basko, D.M. Raman spectroscopy as a versatile tool for studying the properties of graphene. Nat. Nanotechnol. 2013, 8, 235-246. [CrossRef] [PubMed]

81. $\mathrm{Wu}, \mathrm{J} . ;$ Xie, L. Structural Quantification for Graphene and Related Two-Dimensional Materials by Raman Spectroscopy. Anal. Chem. 2019, 91, 468-481. [CrossRef] [PubMed]

82. Pimenta, M.A.; Dresselhaus, G.; Dresselhaus, M.S.; Cançado, L.G.; Jorio, A.; Saito, R. Studying disorder in graphite-based systems by Raman spectroscopy. Phys. Chem. Chem. Phys. 2007, 9, 1276-1291. [CrossRef] [PubMed]

83. Wu, J.B.; Lin, M.L.; Cong, X.; Liu, H.N.; Tan, P.H. Raman spectroscopy of graphene-based materials and its applications in related devices. Chem. Soc. Rev. 2018, 47, 1822-1873. [CrossRef]

84. Pardanaud, C.; Cartry, G.; Lajaunie, L.; Arenal, R. Investigating the Possible Origin of Raman Bands in Defective sp2/sp3 Carbons below $900 \mathrm{~cm}^{-1}$ : Phonon Density of States or Double Resonance Mechanism at Play? C 2019, 5, 79. [CrossRef]

85. Bratek, W.; Świątkowski, A.; Pakuła, M.; Biniak, S.; Bystrzejewski, M.; Szmigielski, R. Characteristics of activated carbon prepared from waste PET by carbon dioxide activation. J. Anal. Appl. Pyrolysis 2013, 100, 192-198. [CrossRef]

86. Jeon, J.-W.; Sharma, R.; Meduri, P.; Arey, B.W.; Schaef, H.T.; Lutkenhaus, J.L.; Lemmon, J.P.; Thallapally, P.K.; Nandasiri, M.I.; McGrail, B.P.; et al. In Situ One-Step Synthesis of Hierarchical Nitrogen-Doped Porous Carbon for High-Performance Supercapacitors. ACS Appl. Mater. Interfaces 2014, 6, 7214-7222. [CrossRef] [PubMed]

87. Macedo, J.S.; Otubo, L.; Ferreira, O.P.; de Gimenez, I.F.; Mazali, I.O.; Barreto, L.S. Biomorphic activated porous carbons with complex microstructures from lignocellulosic residues. Microporous Mesoporous Mater. 2008, 107, 276-285. [CrossRef]

88. Bonso, J.S.; Kalaw, G.D.; Ferraris, J.P. High surface area carbon nanofibers derived from electrospun PIM-1 for energy storage applications. J. Mater. Chem. A 2014, 2, 418-424. [CrossRef]

89. Merlen, A.; Buijnsters, J.G.; Pardanaud, C. A Guide to and Review of the Use of Multiwavelength Raman Spectroscopy for Characterizing Defective Aromatic Carbon Solids: From Graphene to Amorphous Carbons. Coatings 2017, 7, 153. [CrossRef]

90. López-Díaz, D.; López Holgado, M.; García-Fierro, J.L.; Velázquez, M.M. Evolution of the Raman Spectrum with the Chemical Composition of Graphene Oxide. J. Phys. Chem. C 2017, 121, 20489-20497. [CrossRef]

91. Tuinstra, F.; Koenig, J.L. Raman Spectrum of Graphite. J. Chem. Phys. 1970, 53, 1126-1130. [CrossRef]

92. Puech, P.; Kandara, M.; Paredes, G.; Moulin, L.; Weiss-Hortala, E.; Kundu, A.; Ratel-Ramond, N.; Plewa, J.M.; Pellenq, R.; Monthioux, M. Monthioux Analyzing the Raman Spectra of Graphenic Carbon Materials from Kerogens to Nanotubes: What Type of Information Can Be Extracted from Defect Bands? C 2019, 5, 69.

93. Labunov, V.A.; Tabulina, L.V.; Komissarov, I.V.; Mikhnavets, L.A.; Tkach, A.N. Reduction of graphene from graphene oxide in different media. Mater. Phys. Mech. 2019, 41,1-7.

94. Dubale, A.A.; Su, W.N.; Tamirat, A.G.; Pan, C.J.; Aragaw, B.A.; Chen, H.M.; Chen, C.H.; Hwang, B.J. The synergetic effect of graphene on $\mathrm{Cu}_{2} \mathrm{O}$ nanowire arrays as a highly efficient hydrogen evolution photocathode in water splitting. J. Mater. Chem. A 2014, 2, 18383-18397. [CrossRef]

95. Costa, R.; Figueiredo, M.; Pereira, C.M.; Silva, F. Electrochemical double layer at the interfaces of Hg/choline chloride based solvents. Electrochim. Acta 2010, 55, 8916-8920. [CrossRef]

96. Costa, R.; Pereira, C.; Silva, A. Ionic liquids at electrified interfaces for advanced energy/charge storage applications. In Ionic Liquids; Fehrmann, R., Ed.; De Gruyter: Villeurbanne, France, 2019; pp. 101-128.

97. Heimböckel, R.; Hoffmann, F.; Fröba, M. Insights into the influence of the pore size and surface area of activated carbons on the energy storage of electric double layer capacitors with a new potentially universally applicable capacitor model. Phys. Chem. Chem. Phys. 2019, 21, 3122-3133. [CrossRef] [PubMed]

98. Taer, E.; Agustino, A.; Farma, R.; Taslim, R.; Paiszal, M.; Ira, A.; Yardi, S.D.; Sari, Y.P.; Yusra, H.; Nurjanah, S.; et al. The relationship of surface area to cell capacitance for monolith carbon electrode from biomass materials for supercapacitor aplication. J. Phys. Conf. Ser. 2018, 1116, 032040. [CrossRef]

99. Lee, E.J.; Lee, L.; Abbas, M.A.; Bang, J.H. The influence of surface area, porous structure, and surface state on the supercapacitor performance of titanium oxynitride: Implications for a nanostructuring strategy. Phys. Chem. Chem. Phys. 2017, 19, 21140-21151. [CrossRef] 
100. Eguchi, T.; Kanamoto, Y.; Tomioka, M.; Tashima, D.; Kumagai, S. Effect of ball milling on the electrochemical performance of activated carbon with a very high specific surface area. Batteries 2020, 6, 22. [CrossRef]

101. Xu, B.; Wu, F.; Chen, R.; Cao, G.; Chen, S.; Wang, G.; Yang, Y. Room temperature molten salt as electrolyte for carbon nanotubebased electric double layer capacitors. J. Power Sources 2006, 158, 773-778. [CrossRef]

102. Schutjajew, K.; Yan, R.; Antonietti, M.; Roth, C.; Oschatz, M. Effects of carbon pore size on the contribution of ionic liquid electrolyte phase transitions to energy storage in supercapacitors. Front. Mater. 2019, 6, 65. [CrossRef]

103. Zdolšek, N.; Rocha, R.P.; Krstić, J.; Trtić-petrović, T.; Šljukić, B.; Figueiredo, J.L.; Vujković, M.J. Electrochemical investigation of ionic liquid-derived porous carbon materials for supercapacitors: Pseudocapacitance versus electrical double layer. Electrochim. Acta 2019, 298, 541-551. [CrossRef]

104. Iakunkov, A.; Skrypnychuk, V.; Nordenström, A.; Shilayeva, E.A.; Korobov, M.; Prodana, M.; Enachescu, M.; Larsson, S.H.; Talyzin, A.V. Activated graphene as a material for supercapacitor electrodes: Effects of surface area, pore size distribution and hydrophilicity. Phys. Chem. Chem. Phys. 2019, 21, 17901-17912. [CrossRef] [PubMed] 